ISSN: 0213-2060

DOI: http://dx.doi.org/10.14201/shhme201432187213

\title{
PAISAJE FORESTAL Y REPRESENTACIÓN SOCIAL EN CASTILLA (SIGLOS XIV-XVI). LOS MONTES DE SAN SALVADOR DE OÑA (BURGOS) ${ }^{1}$
}

\author{
Forest Landscape and Social Memory in Castile (14 ${ }^{\text {th }}-16^{\text {th }}$ Centuries). \\ The Forest of San Salvador de Oña (Burgos)
}

\author{
Francisco REYES TÉLLEZ \\ Facultad de Ciencias Jurídicas y Sociales. Universidad Rey Juan Carlos. Paseo de los Artilleros, s/n. E-28032 \\ VICÁLVARO (Madrid). C. e.: francisco.reyes@urjc.es \\ Gonzalo VIÑUALES FERREIRO \\ Facultad de Ciencias Juridicas y Sociales. Universidad Rey Juan Carlos. Paseo de los Artilleros, s/n. E-28032 \\ VICÁLVARO (Madrid).C.e.: gonzalo.vinuales@urjc.es
}

Recibido: 2013-03-19

Revisado: 2013-07-23

Aceptado: 2013-09-20

BIBLID [0213-2060(2014)32;187-213]

RESUMEN: El objetivo principal de este artículo es tratar de analizar la representación social del paisaje forestal perteneciente al señorío del monasterio de San Salvador de Ońa (Burgos), durante los siglos XIV-XVI, a partir de las descripciones que se realizan del mismo en la documentación judicial relacionada con pleitos, pesquisas, etc. por el uso y aprovechamiento de los bosques y montes, para procurar conocer cuál era la construcción simbólica de esos paisajes de los distintos agentes sociales, e intentar valorar si esa forma de aproximarnos al territorio nos puede aportar nuevos enfoques o posibilidades de interpretación en el estudio de esa realidad.

1 Este trabajo ha sido realizado en el marco del Proyecto del Plan Nacional de I+D+i «Los fundamentos del Espacio Europeo (II): Identidades locales y Estados emergentes en la Europa altomedieval» (Ref. HAR2010-21950-C03-01). 
FRANCISCO REYES TÉLLEZ Y GONZALO VIÑUALES FERREIRO PAISAJE FORESTAL Y REPRESENTACIÓN SOCIAL EN CASTILLA (SIGLOS XIV-XVI). LOS MONTES DE SAN SALVADOR DE OÑA (BURGOS)

Palabras clave: Paisaje. Bosques. Percepción. Representación Social. Castilla. San Salvador de Ońa (Burgos). Siglos XIV-Xvi.

ABSTRACT: The main objective of this article is to analyze the social memory of the forest landscape of the San Salvador de Oña (Burgos) monastery during the $14^{\text {th }}-16^{\text {th }}$ Centuries across the descriptions of that landscape in the judicial documentation to find out the symbolic vision of these landscapes from the social groups, and try to understand if this approach offers us new perspectives or possibilities for the understanding of this reality and the landscape.

Keywords: Landscape. Forest. Perceptions. Social Memory. Castile. San Salvador de Ońa (Burgos). $14^{\text {th }}-16^{\text {th }}$ Centuries.

SUMARIO: 1 El Paisaje: percepción y representación social. 2 Los montes de San Salvador de Oña (Burgos) en los siglos XIV-Xvi. 2.1 Descripción del paisaje forestal: sus atributos. 2.2 Interpretación del paisaje forestal: la toponimia. 2.3 Valoración del paisaje forestal: la representación social.

\section{El PAISAJE: PERCEPCIÓN Y REPRESENTACIÓN SOCIAL}

El concepto «paisaje» es complejo y polisémico, bien por la variedad de disciplinas que se han aproximado a su estudio y análisis -desde la Estética, el Arte, o la Geografía, hasta la Ecología o la Arqueología-, bien por su profunda interrelación entre lo objetivo y lo subjetivo. No obstante, parece constatarse una tendencia a aceptar de una manera más o menos unánime como definición común, flexible y no excluyente del término, la que planteó el Convenio Europeo del Paisaje aprobado en Florencia en el año 2000, y que entró en vigor en España a partir de marzo del año 2008: "Cualquier parte del territorio tal y como la percibe la población, cuyo carácter sea el resultado de la acción y la interacción de factores naturales y/o humanos» ${ }^{2}$. Si atendemos a esta redacción, no exenta de cierta polémica o discrepancia, denotamos que se ha otorgado un papel protagonista a la idea de la percepción de la población, a la «dimensión subjetiva» de la misma, plural e integradora, pero cambiante al mismo tiempo. Siguiendo el comentario a dicha definición que propone Rafael Mata, habrá que reconocer que «en la percepción, a partir de miradas múltiples y cambiantes en el tiempo, reside una parte muy importante de la carga cultural del paisaje, una carga que se manifiesta tanto en la materialidad de cada fisonomía modelada por la acción humana, como en sus imágenes y representaciones sociales» ${ }^{3}$. El paisaje aparecerá, así, dotado de un «carácter», según la definición aludida,

2 Paül i Carril, Valerià; Sancho Reinoso, Alexis y Tort Donada, Joan. "El marco conceptual de los paisajes de la agricultura». En Molinero, Fernando; OJedA, Juan Francisco y Tort, Joan (coords.). Los paisajes agrarios de España. Caracterización, evolución y tipificación. Madrid, 2011, p. 17.

3 «El paisaje es, en su configuración formal, la huella de la sociedad sobre la naturaleza y sobre paisajes anteriores, la marca o señal que imprime "carácter" a cada territorio. De aquí arranca justamente el 
de una impronta dinámica y cambiante, fruto de las actividades pasadas y presentes de una colectividad sobre la naturaleza en transformación. Y en virtud de esas actividades el paisaje pasará a convertirse en objeto de estudio histórico ${ }^{4}$.

$\mathrm{Al}$ incidir en la semántica de la percepción, el paisaje es entendido como el territorio percibido desde la capacidad psicológica del individuo concreto para a través de sus sentidos, especialmente de la vista, aprehender un espacio, visualizarlo, contemplarlo, comprenderlo e interpretarlo. Es un proceso que está claramente vinculado a fenómenos psicológicos y neurológicos de cada persona en particular, que van ligados al desarrollo de la manera de captar esos espacios. Pero esta comprensión no puede desligarse de su componente cultural ${ }^{5}$. Tal es el peso de lo cultural en la esencia de la noción de "paisaje», que David Arnold en un conocido ensayo lo denomina «artefacto cultural»; y lo explica con el ejemplo de que no se puede afirmar que América fuera descubierta por Colón o por otros exploradores, sino que fue «inventada» por él y sus continuadores. Solamente a través de la imaginación, de la asociación simbólica, de dotar de significados «metafóricos» a realidades desconocidas, y con el transcurso de varias décadas, el nuevo espacio físico americano fue interpretado como un continente, como una categoría geográfica identificable a Europa, Asia o África ${ }^{6}$. Esta concepción del paisaje como hecho mental, no solo como fenómeno individual sino preferentemente colectivo, fue definida como «noosfera» por Vernadsky en 1945.

Frente a una postura centrada en la percepción, nuestro planteamiento pretende analizar el paisaje desde la concepción de la representación del paisaje. Yves Luginbülh ha tratado de precisar los matices que existen entre la idea de percibir y la idea de representar un paisaje. Según hemos indicado, en el caso de la percepción de un paisaje se prima al individuo frente al colectivo, mientras que la representación del paisaje exige necesariamente un valor social, pues se produce en el contexto del grupo. En palabras de Luginbülh,

cuando nos referimos a las representaciones sociales del paisaje debemos pensar en lo que representa el paisaje para un grupo social. Las representaciones sociales remiten a una construcción simbólica colectiva del objeto paisaje. Ahora bien, esta construcción está profundamente marcada por las relaciones sociales, bien entre individuos bien entre grupos

entendimiento del paisaje como patrimonio, un hecho que tanto aproxima hoy a las políticas paisajísticas y de patrimonio cultural». Mata Olmo, Rafael. "Paisaje y territorio. Un desafío teórico y práctico». En Sánchez Pérez-Moneo, Luciano y Troitiño Vinuesa, Miguel Ángel (coords.). Agua, territorio y paisaje: de los instrumentos programados a la planificación programada. V Congreso Internacional de Ordenación del Territorio. Madrid, 2009, pp. 1003-1004.

4 Tosco, Carlo. «El paisaje histórico: instrumentos y métodos de investigación». En Maderuelo, Javier (dir.). Paisaje e Historia. Madrid, 2009, pp. 89-110.

5 «El paisaje es, por tanto, un concepto complejo, resultado de la combinación de aspectos diversos como son los naturales, los históricos y los funcionales, pero adquiere también valor simbólico y subjetivo al ser considerado reflejo de la herencia cultural de un pueblo, de su identidad y resultado de unas prácticas históricas ejercidas por un grupo humano sobre el territorio». Hernández Hernández, María. «El paisaje como seña de identidad territorial: valorización social y factor de desarrollo. ¿Utopía o realidad?». Boletín de la Asociación de Geógrafos Españoles, 2009, vol. 49, p. 170.

6 Arnold, David. La naturaleza como problema histórico. El medio, la cultura y la expansión de Europa. México, 1996, pp. 126-127. 
FRANCISCO REYES TÉLLEZ Y GONZALO VIÑUALES FERREIRO PAISAJE FORESTAL Y REPRESENTACIÓN SOCIAL EN CASTILLA (SIGLOS XIV-XVI). LOS MONTES DE SAN SALVADOR DE OÑA (BURGOS)

sociales. [...] Un individuo no podrá, en la elaboración de su representación del paisaje, liberarse de las relaciones que mantiene con su vecino, por ejemplo, -lo que es perfectamente comprensible-, pero tampoco de sus relaciones con otros grupos que intervienen en el paisaje o en su espacio vital. La manera como este individuo se representa el paisaje está profundamente ligada a lo que piensan los demás; la construcción simbólica del paisaje pasa por esta confrontación con las construcciones simbólicas de otros actores ${ }^{7}$.

De tal manera desempeña una función primordial sobre el paisaje la estructura simbólica, que hay algunos autores que hablan de recreación en el sentido que nosotros hemos empleado la expresión representación social, y que habría una última fase, posterior a la recreación, que respondería a lo que ellos han dado en llamar simbolización ${ }^{8}$. No obstante, este matiz está orientado más al desarrollo de políticas de uso y conservación del paisaje que relacionado con su carga histórica. En una línea de análisis próxima, Nohl en 2001 ya había planteado la existencia de cuatro niveles de relación entre el observador y el paisaje. Partiendo de una base perceptiva de tipo sensorial, se pasaría a una segunda etapa expresiva, en la que se asocian o vinculan esas percepciones con emociones, pulsiones, o sentimientos. La tercera fase vendría determinada por la captación sintomática del paisaje, en donde lo percibido se convierte en referente de otra realidad paisajística no visualizable; y, en cuarto lugar, se situaría un nivel ya simbólico, que alude a sistemas de valores, maneras de vivir, etc.?

Este proceso necesariamente ha de responder a la idea de que el lenguaje (y su interpretación, intertextualidad, etc.) nos ha de poder ofrecer información acerca de una forma espacial visible (un paisaje) ante la que el individuo y el grupo social podría comportarse, actuar o responder de una forma previsible e incluso predeterminada, pero ante la que se comporta de la forma esperada de acuerdo a su propia construcción simbólica, obedeciendo a sus patrones simbólico-sociales ${ }^{10}$. Como afirma John Moreland acerca de sus estudios de arqueología del paisaje en el valle de Roystone Grange, especialmente sobre la cruz de Bradbourne, «lo que faltaba en nuestras reflexiones sobre la vida cotidiana

7 LuginbüLh, Yves. «Las representaciones sociales del paisaje y sus evoluciones». En Maderuelo (dir.), Paisaje y territorio, pp. 146-147.

8 «Simbolización: Convergencia de percepciones, identificaciones, y representaciones creativas, que se traduce en una valoración institucional, patrimonial y simbólica de algunos paisajes, que quedan significados por su genuina singularidad y por su producción de autocomplacencia institucional y social». DeLgado Bujalance, Buenaventura; Ojeda Rivera, Juan Francisco; Rubio Tenor, Marta y Silva Pérez, Rocío. «Paisajes agrarios españoles. Desde sus bases territoriales a sus representaciones, catalogación y arquetipos». En Molinero, Ojeda y Tort (coords.), Los paisajes agrarios de España, p. 147.

9 NohL, Werner. «Sustainable landscape use and aesthetic perception. Preliminary reflections on future landscapes aesthetics». Landscape Urban Planning, 2001, vol. 54, pp. 223-237.

10 «En definitiva, el carácter del paisaje como registro de la memoria y la identidad sociales tiene grandísimas implicaciones epistemológicas sobre los métodos y las posibilidades de "deconstruirlo" para llegar a conocer la sociedad que lo generó. Más aún porque, salvo casos excepcionales, no podemos aislar un espacio concreto humanizado, sino más bien procesos de cambio social en relación con procesos de cambio espacial». Escalona, Julio; Alfonso, Isabel y Reyes, Francisco. «Arqueología e historia de los paisajes medievales: apuntes para una agenda de investigación». En Garrabou, Ramón y NAREdo, José Manuel (eds.). El paisaje en perspectiva histórica: formación y transformación del paisaje en el mundo mediterráneo. Zaragoza, 2008, p. 104. 


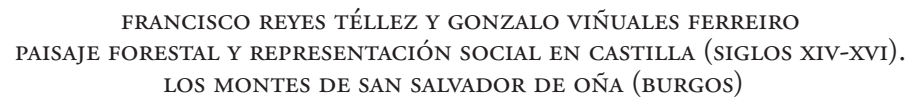

en Roystone Grange era cierto reconocimiento de que el ritual estructuraba la rutina, que lo mundano estaba impregnado por lo "maravilloso"»"

\section{Los montes de San Salvador de Oña (Burgos) en los siglos Xiv-XVi}

En el contexto de la renovación metodológica que han experimentado los estudios sobre el paisaje en las últimas dos décadas ha supuesto un punto de inflexión el desarrollo de la propuesta Landscape Character Assessment (LCA), desarrollada por The Countryside Agency y por Scottish Natural Heritage que se puede traducir aproximadamente en términos de "estimación del carácter paisajístico»" ${ }^{12}$. Se supera, en cierto modo, el pretendido peso de lo visual (y estético) en el paisaje para desarrollarlo desde una perspectiva relacional notablemente integradora, en torno a cuatro grandes dimensiones: la biofísica, la administrativa, la socioeconómica y técnica, y la humana y estética ${ }^{13}$. No resulta sencillo aplicar al estudio de los paisajes históricos y sus representaciones, modelos metodológicos que responden a las necesidades actuales de consideración o comprensión del paisaje, pues es sumamente complicado estudiar los fenómenos biofísicos de manera fehaciente ${ }^{14}$. La amplia revisión que han experimentado los estudios del paisaje y la aparición de términos como el de «paisaje cultural» han facilitado la integración y el interés por los fenómenos de representación social ${ }^{15}$. Dentro de la configuración sistémica del paisaje nos ha resultado útil partir de la propuesta de cartografía del paisaje que ofrecen Gómez Alzate y Londoño López, dentro de su categorización del mismo como un «sistema visual holístico», y cuya aplicación se basa en tres fases de análisis: descripción, interpretación y valoración. La percepción visual del paisaje conecta con la representación cultural del mismo gracias, en gran medida, al empleo del lenguaje:

El conocimiento del paisaje debe comenzar con aprender a decir lo que se ve, el vocabulario visual debe enriquecerse para poder describir adecuadamente las diversas situaciones geográficas y humanas que se suceden en él, pues el paisaje permanece más en el lenguaje y existe la tendencia de suprimir lo que no se puede expresar; como los ojos exploran el campo visual y resumen ciertos elementos, es importante visualizar el

11 Moreland, John. «Lo maravilloso y lo mundano en la Arqueología medieval». En Jiménez Puertas, Miguel y García-Contreras Ruiz, Guillermo. Paisajes históricos y Arqueología medieval. Granada, 2011, p. 11.

12 Sunmwick, Carys. Landscape character assessment. Guidance for England and Scotland. The Countryside Agency and Scottish Natural Heritage, 2002.

13 El término "carácter» se define como: «una conjunción particular, reconocible y consistente de elementos presentes en un determinado paisaje que lo hacen diferente de otros». Gómez Zotano, José y Riesco Chueca, Pascual. Marco conceptual y metodológico para los paisajes españoles. Aplicación a tres escalas espaciales. Sevilla, 2010, p. 25.

${ }_{14}$ Frolova, Marina. «El lenguaje científico del paisaje: entre las representaciones culturales y las modelizaciones geográficas». En Ortega Cantero, Nicolás; García Álvarez, Jacobo y Mollá RuizGómez, Manuel. Lenguajes y visiones del paisaje y del territorio. Madrid, 2010, p. 288.

15 Luchía, Corina. "Los aldeanos y la tierra: percepciones campesinas en los concejos castellanos, siglos XIV-XVI». Studia Historica. Historia Medieval, 2011, vol. 29, pp. 207-228. 
FRANCISCO REYES TÉLLEZ Y GONZALO VIÑUALES FERREIRO PAISAJE FORESTAL Y REPRESENTACIÓN SOCIAL EN CASTILLA (SIGLOS XIV-XVI). LOS MONTES DE SAN SALVADOR DE OÑA (BURGOS)

idioma del paisaje y evaluar su vocabulario para analizar cómo el despliegue visual puede conceptuarse como paisaje ${ }^{16}$.

A partir del supuesto de que «el paisaje existe por su visibilidad» y que la percepción y el análisis visual del paisaje dejan improntas en la expresión y en el lenguaje (topónimos, descripción de paisajes, apeos, visitas, clima, hitos culturales, referencias, etc.), reflejando unos determinados usos y representaciones sociales y culturales, vamos a analizar una serie de referencias documentales que contienen información relativa a los paisajes forestales del monasterio de San Salvador de Ońa (Burgos) durante los siglos XIV al XVI, para tratar de apreciar mediante un modelo fenomenológico la construcción simbólica que de esos paisajes tenían los diferentes agentes que los vivían ${ }^{17}$.

La documentación histórica conservada relativa al monasterio de San Salvador de Oña desde su fundación hasta el año 1350 está publicada ${ }^{18}$. A ella hay que añadir la documentación transcrita en su tesis doctoral por Francisco Ruiz Gómez que se mantiene aún inédita, aunque se puede consultar en el catálogo de tesis doctorales de la Universidad Complutense de Madrid, y cuyo valor añadido es que aporta los documentos conservados en el archivo de la iglesia parroquial de San Juan de Oña ${ }^{19}$. Por otro lado, existen diversos trabajos sobre Ońa en los que se aporta varia documentación (transcripciones, regestos y/o citas) aunque no se presentan ni de forma estructurada ni sistemática, cronológica o temáticamente ${ }^{20}$. Entre estos últimos podríamos reseñar, tanto por su actualidad como por la cantidad y variedad de trabajos que incluyen, las monografías San Salvador de

16 Gómez Alzate, Adriana y Londoño López, Felipe César. Paisajes y nuevos territorios (en red). Cartografias e interacciones en entornos visuales y virtuales. Barcelona, 2011, pp. 83-84.

17 «El paisatge segueix essent el resultat d'una transformació col-lectiva de la natura; és la projecció cultural d'una societat en un espai determinat. I no només en allò referent a la seva dimensió material, sinó també a la seva dimensió espiritual i simbòlica. El paisatge és, per tant, un concepte enormement impregnat de connotacions culturals i es pot interpretar com un dinàmic codi de símbols que ens parla de la cultura del seu passat, del seu present i potser també de la del seu futur. La legibilitat semiòtica del paisatge, això és el grau de descodificació dels seus símbols, pot ser més o menys complexa, però està lligada, en qualsevol cas, a la cultura que els produeix». Nogué i FonT, Joan. «Paisatge i identitat territorial en un context de globalització». Treballs de la Societat Catalana de Geografia, 2005, vol. 60, p. 178.

18 Álamo, Juan del. Colección diplomática de San Salvador de Oña (1011-1284). Madrid, 1950. Oceja Gonzalo, Isabel. Documentación del monasterio de San Salvador de Oña (1032-1284). Burgos, 1983; Documentación del monasterio de San Salvador de Oña (1285-1310). Burgos, 1986; Documentación del monasterio de San Salvador de Oña (1311-1318): Índices (1031-1318). Burgos, 1986; Documentación del monasterio de San Salvador de Oña (1319-1350). Burgos, 1986.

19 Ruiz Gómez, Francisco. Las formas del poblamiento rural en la Bureba en la Baja Edad Media. La villa de Oña. Madrid, 1988. La monografía resultado de esta investigación ha sido publicada bajo el título Las aldeas castellanas en la Baja Edad Media. Madrid, 1990, pero en una versión que no incluye los valiosos apéndices documentales.

20 Bonaudo de Magnani Gómez, Marta. «El monasterio de San Salvador de Ońa. Economía agraria y sociedad rural». Cuadernos de Historia de España, 1970, vol. LI-LII, pp. 42-122; Diago Hernando, Máximo. «Fuentes de ingresos y situación económica del monasterio de Oña en los siglos Xv y xvI». Anuario de Estudios Medievales, 1998, vol. 28, pp. 451-486; e ÍDEM. "La tutela nobiliaria sobre los monasterios benedictinos castellanos en la Baja Edad Media: relaciones entre los Velasco y el monasterio de San Salvador de Ońa». Hispania Sacra, 2004, vol. 56, n. ${ }^{\circ}$ 113, pp. 69-102; Isla Frez, Amancio. «Oña, innovación monástica y política en torno al ańo mil». Hispania, 2007, vol. 67, n. ${ }^{2} 25$, pp. 151-172. 
Oña. Mil años de historia ${ }^{21}$; y Oña. Un milenio. Actas del Congreso Internacional sobre el Monasterio de Oña (1011-2011)22, así como el dossier monográfico sobre el milenario de Oña que se publicó en el número 24 de la Revista Circunstancia ${ }^{23}$. El legado documental de Oña es ingente. Los documentos depositados en el Archivo Histórico Nacional de Madrid son los más numerosos conservados en relación con ningún otro monasterio medieval castellano ${ }^{24}$. La potencia documental alcanza, solamente para la sección de Clero, 1.676 pergaminos, 165 legajos y 138 libros.

Entre los diversos fondos documentales conservados relativos al monasterio benedictino de Ońa hemos localizado y seleccionado aquellos que aluden a pesquisas, disputas y/o procesos judiciales sobre el uso y el aprovechamiento de bosques y montes entre el monasterio y diversos concejos como los de Arroyuelo, Villapanillo, Tamayo, Bentretea, Terminón o Soto (de Bureba) con una horquilla cronológica que transcurre entre los ańos 1320 y 1530, en la medida en que son casi los únicos documentos que nos transmiten información sobre este asunto debido preferentemente a la existencia de un conflicto que deja su huella en la documentación ${ }^{25}$. ¿Reflejará la representación social del paisaje la idea de conflicto? ¿Estará presente en la concepción del documento el medio ambiente, el entorno, o la naturaleza en la mente de los redactores?, o, como expresa Esther Pascua, tanto monasterios como obispados son instituciones con escasa sensibilidad medioambiental al primar su interés por la renta y por la definición de los límites territoriales de su señorío y así se refleja en su producción textual ${ }^{26}$.

\subsection{Descripción del paisaje forestal: sus atributos}

El soporte natural es un sustrato necesario en la descripción, interpretación y representación social del paisaje, ya sea en sus caracteres morfológicos, edafológicos y/o

21 Sánchez-Domingo, Rafael y Palomero Aragón, Félix (coords.). San Salvador de Oña. Mil años de Historia. Zamudio, 2011.

22 Sánchez-Domingo, Rafael (coord.). Oña. Un milenio. Actas del Congreso Internacional sobre el Monasterio de Oña (1011-2011). Zamudio, 2012.

23 Escalona, Julio y Reyes, Francisco. «Los orígenes de Ońa y el estudio del territorio»; Palomero, Félix y Palomero, Irene. "La fábrica de San Salvador de Oña: épocas medieval y moderna»; SÁNchezDomingo, Rafael. «Dominio y jurisdicción de Oña»; SuÁrez Bilbao, Fernando y Viñuales, Gonzalo. «El monasterio de San Salvador de Ońa en la Baja Edad Media». Revista Circunstancia, 2011, vol. 24.

24 Cruz Herranz, Luis Miguel de la. «El fondo del Monasterio de Oña en el archivo Histórico Nacional». En Sánchez-Domingo, Oña. Un milenio, pp. 294-322.

25 «En tal sentido, la capacidad que tienen las fuentes escritas es menor, aunque no debe en absoluto descuidarse, porque nos dan la imagen socialmente construida de los espacios rurales, tan importante como la constatación física de los mismos. Y, sobre todo, nos proporcionan una información relevante sobre la organización socioeconómica. Por tales razones, conviene tener en cuenta la, por otro lado, parca información sobre el espacio rural proveniente de leyes, hagiografías, crónicas u otro tipo de textos, aunque su pretensión jamás sea la de describir fielmente el territorio». Martín VIsO, Iñaki. «Un mundo en transformación: los espacios rurales en la Hispania post-romana (siglos v-viI)». En Caballero Zoreda, Luis; Mateos Cruz, Pedro y Cordero Ruiz, Tomás (eds.). Visigodos y omeyas. El territorio. Mérida, 2012, p. 32.

26 Pascua Echegaray, Esther. Señores del paisaje. Ganadería y recursos naturales en Aragón, siglos XIII al XVII. Valencia, 2012, p. 43. 
FRANCISCO REYES TÉLLEZ Y GONZALO VIÑUALES FERREIRO PAISAJE FORESTAL Y REPRESENTACIÓN SOCIAL EN CASTILLA (SIGLOS XIV-XVI). LOS MONTES DE SAN SALVADOR DE OÑA (BURGOS)

climatológicos ${ }^{27}$. La toponimia así lo demuestra, si atendemos a la proporción de términos que aparecen recogidos en la documentación según planteamos en el apartado siguiente. Incluso están presentes en la propia apreciación que se tiene del entorno geográfico, en su accesibilidad, en su propia topografía ${ }^{28}$ y en sus recursos bióticos ${ }^{29}$. En esa posición se fundamentan gran parte de los estudios geográficos del paisaje o aquellos planteados desde la óptica de la Geografía del Medio Ambiente ${ }^{30}$. De esta manera se expresa, por ejemplo, en la definición del concepto «paisaje» que nos ofrecen F. Burel y J. Baudry en el libro Ecología del paisaje: "Paisaje: porción de espacio concerniente a la escala de las actividades humanas. Viene definido por su heterogeneidad espacial y temporal, por las actividades humanas que en él se desarrollan y por su ambiente» ${ }^{31}$. Pero para ello habrá que procurar alejarse de una cierta visión reduccionista o exclusivista ${ }^{32}$.

Gonzalo Madrazo en su estudio sobre los bosques de la vertiente norte de la Sierra de Guadarrama define el concepto de «paisaje forestal» como: «un concepto de síntesis, que engloba tanto los elementos inmediatamente visibles del mismo, caso de la vegetación,

27 Martínez de Pisón, Eduardo. «Imagen de la naturaleza de las montañas». En Martínez DE Pisón, Eduardo (dir.). Estudios sobre el paisaje. Murcia, 2000, pp. 15 y 18.

28 1542: Licencia para erigir en parroquia la hermita de San Martín de Presa y Villanueva. «Fernando de Santisteban y Pedro de Rozas por nos mismo y en nombre y como procuradores que somos de los otros vecinos y moradores de los lugares de Villanueba y Presa, feligreses y parroquianos de la Iglesia de Santisteban del lugar de Carranza que pleno iure es sujeta y pertenece a Vuestra Paternidad, Prior, Monges y Convento deste Monasterio, parecemos ante Vuestra Paternidad y decimos que los dichos lugares de Villanueba y Presa están distantes y apartados de la dicha Iglesia Parroquial de Santisteban dos tercios de una legua, y el camino es fraguoso por ser en montañas, y en tiempo de invierno, como cargan muchas nieves, crecidas y avenidas de aguas, los vecinos y moradores de los dichos lugares y la gente que en ellos an, los días de Pascuas, Domingos y Fiestas y otros días, no pueden ir a oír misa y los otros divinos oficios, según y como son obligados, y lo harían si más cerca estuviese donde pudiesen oír misa. Y ansí mismo pasan muy gran trabajo por la mucha distancia en llevar a sepultar los difuntos y bautizar los niños que nazen a la dicha Iglesia especialmente en tiempo de invierno, $y$ como ai viejos e impedidos, mozos y mozas, estanse mucho tiempo sin oir misa, y los otros dichos divinos oficios lo qual es en gran dańo y perjuicio de sus ánimas y conciencias». Archivo Histórico Nacional (en adelante, AHN). Clero. Legajo 1214.

29 Aunque no sean objeto directo de interés en estas páginas, las referencias textuales a recursos cinegéticos, que tendrían una importancia demostrada, tanto por la latitud, como el clima, y la altura, así como por la densidad de estos bosques, no aparecen documentados en los pleitos. Solamente hemos localizado alusiones a fauna con ocasión de mencionar los estragos de los lobos en los terrenos del concejo de Cornudilla: «Muy reverendo señor. Nos el concejo de Cornudilla vasallos, y servidores de su muy reverenda paternidad vesamos las manos de su merçed y le hazemos saber por quanto el estrago de los lobos es mucho y no hay guarda ninguna que se pueda defender dellos, por tanto humilmente le suplicamos nos quiera hazer gracia y merçed en el su término de la sierra para hazer un corral donde se recoja el ganado de noche la qual licencia pedimos y suplicamos sernos conçedida por el tiempo que su reverenda paternidad mandare deste su logar de Cornudilla». AHN. Clero. Legajo 1295.

30 Clément, Vincent. De la marche-frontière au pays-des-bois. Forêts, sociétés paysannes et territoires en Vieille-Castille (XI'-XX siècle). Madrid, 2002.

31 Burel, Françoise y Baudry, Jacques. Ecología del paisaje. Conceptos, métodos y aplicaciones. Madrid, 2002, p. 352.

32 «El conocimiento de los geosistemas y de los ecosistemas es evidentemente indispensable, pero no nos hace avanzar un solo paso en la determinación de los valores paisajísticos, que son socioculturales. El análisis objetivo de un biotopo, la medida del grado de contaminación de un río no tienen, literalmente, nada que ver con el paisaje». Roger, Alain. Breve tratado del paisaje. Madrid, 2007. 
como aquellos otros - menos perceptibles- que constituyen la estructura en la que se sostiene su apariencia, caso de la propiedad o los aprovechamientos forestales, amén de otros elementos perceptivos (estéticos), representativos (identitarios), o discursivos» ${ }^{33}$. No es objeto aquí de análisis el estudio de los factores bióticos o abióticos, aunque somos conscientes de que aspectos tales como las condiciones edafológicas y climatológicas (insolación, humedad, temperatura, etc.) así como las propias de la cubierta vegetal son imprescindibles para aproximarnos a un correcto conocimiento del paisaje $\mathrm{e}^{34}$.

Dentro de las diversas unidades del paisaje que se podrían definir, aquí nos vamos a ceñir preferentemente a los bosques. En relación con la masa forestal, de acuerdo a las enumeraciones o descripciones que se desprenden de la documentación judicial, las especies arbóreas predominantes en los montes y bosques onienses eran el roble, el haya, la encina y el tejo. Lo sabemos porque la documentación dice textual y repetidamente que los vecinos de los diversos concejos a los que se les concede la merced de poder coger madera o leńa de esos montes y bosques, tienen taxativamente prohibido cortarla si pertenece a alguna de estas especies ${ }^{35}$. Las cuatro especies generan riqueza. Su madera es noble y resistente; su fruto valioso. Son también especies de crecimiento lento. Es evidente la importancia de estos árboles, el valor de su madera, la tradición de respetarlos y no talarlos, pues otras instancias se han de beneficiar de ellos. Tampoco se permite cortar las ramas de los árboles o de matorrales (leńa verde) con el evidente objetivo de evitar la deforestación. Las licencias que se concederán a los vecinos de los distintos concejos hacen referencia expresa a que solamente se les concede permiso para cortar lenna seca, horcas, e horçillas, e palos, pero nunca de las especies citadas. Esta mención a leńa seca no nos aclara de qué tipo de madera estamos hablando. Esta forma de recogida selectiva de madera tenía diversas utilidades y aprovechamientos, preferentemente de uso doméstico ${ }^{36}$. Se usa como combustible para calentar las casas y hogares ${ }^{37}$. Se emplea asimismo como material para arreglar y reparar parrales y viñas ${ }^{38}$, mejorar las viviendas

\footnotetext{
33 Madrazo, Gonzalo. La evolución del paisaje forestal en la vertiente segoviana de la Sierra de Guadarrama. Valladolid, 2010.

34 Una aproximación a la concepción que el hombre medieval pudo configurarse de su entorno medioambiental la encontramos en RuCQUoI, Adeline. "La percepción de la naturaleza en la Alta Edad Media». En Sabaté, Flocel (ed.). Natura i desenvolupament. El Medi Ambient a l'Edat Mitjana. Lleida, 2007, pp. 73-99.

35 «Pero entiéndase que la dicha liçençia se les da con tal condiçión que non lieven de los dichos montes lenna verde salvo seca e que non corten maderas de robre ni de enzina ni de faya ni de teja». AHN. Clero. Legajo 1295 (1496. Licencia que dio el abad Fray Andrés de Çereso a los lugares de Arroyuelo y Villapanillo para cortar los nuestros montes).

36 «En la propia casa campesina se fabricaban todos los instrumentos y accesorios de madera: el palo de la guadaña, el mango de la hoz, o el de la haya, el bastidor del rastrillo, y las piezas de madera del arado. Los campesinos obtenían la madera necesaria en los bosques comunales». RösENER, Werner. Los campesinos en la Edad Media. Barcelona, 1990, p. 136.

37 1454, septiembre, 24. Ońa. Sentencia entre Bentretea y Terminón sobre los montes e pastos: «Pero fallo que pueden e deben cortar en los dichos montes estacas para sus vinnas e lenna para quemar en sus casas». AHN. Clero. Legajo 1214.

38 1520, noviembre, 22. Arroyuelo: «Petición de los de Arroyuelo porque tienen necesidad de horcas, horçillas para sus parrales y vińas, y leña seca para proveer sus casas de los montes de la Horadada. Juan González, escribano, por mandado del merino e regidores». AHN. Clero. Legajo 1295.
} 
FRANCISCO REYES TÉLLEZ Y GONZALO VIÑUALES FERREIRO PAISAJE FORESTAL Y REPRESENTACIÓN SOCIAL EN CASTILLA (SIGLOS XIV-XVI). LOS MONTES DE SAN SALVADOR DE OÑA (BURGOS)

y casas de los vecinos ${ }^{39}$, puentes ${ }^{40}$, o los molinos del monasterio. ${ }^{41}$ Quizá una de sus funciones pudiera ser para que su bellota sirviera para alimentar a cerdos, etc. Podría ir destinada a alguna ferrería, o ser utilizada para la construcción naval ${ }^{42}$, pero no hemos encontrado ni en los libros de cuentas ni en otros asientos contables anotaciones de ingresos o gastos por este o por otros conceptos parecidos. Tampoco se documentan demandas de robos de madera, pero sí incendios en los que se queman los árboles vedados $^{43}$. Ahora bien, sí que sabemos que una parte de la madera se destina asimismo a la producción de carbón, pues esta práctica está documentada en los montes de Oña ${ }^{44}$. No contamos casi con datos para conocer cómo era el trabajo de los carboneros o acerca del control sobre las fraguas ${ }^{45}$, pero da la impresión de que existe un control estricto y férreo de esa actividad por parte del monasterio ${ }^{46}$, aunque las ordenanzas de Ońa del siglo XV, que atienden a cuestiones del precio de las piezas de hierro, no aportan ninguna información sobre ello. No obstante, en el conjunto de recursos naturales que son objeto de disputa o litigio hay otros que también se verán amenazados y, por ello, defendidos: «E otrosí, que van e enbian a los sus ríos e a los sus piélagos del dicho su monasterio, e de los otros sus monasterios e caseríos e villas e logares, e que ge los corren e ge los pescan los salmones e las truchas e los otros pescados por fuerça e contra su voluntat, non aviendo razón por qué los cortar dichos sus montes, nin por qué les tomar las perdices dellos» ${ }^{47}$.

39 1528, septiembre, 23. Arroyuelo: «Johan de Lomanna cura clérigo deseno de Sant Nicolás desta su villa de Arroyuelo beso las manos de su paternidad e se obra como la neçesydad me a causado a dar enojo a su reverenda paternidad, haziéndole saber commo Dyos quiso que se me cayese un pedaço de una casa de la qual tengo mucha neçesidad y segund el tiempo corre e las neçesidades son tan grandes que aunque onbre quiera hacerla non puede aber madera por su derecho». AHN. Clero. Legajo 1295.

40 1483: «Después desto pagué a treinta e siete carpenteros que andovieron en faser la estacada de la puente de Tamayo [...] que andovieron a traer todas las estacas e maderas que fueron menester en que entraron treynta e çinco carros e tres carpenteros». AHN. Clero. Legajo 1297.

41 «Otrosí señor, porque para el martes plasyendo a Dios tienen que ir a dereçar los sus molinos de Çevolleros que serán menester estaquas, deven mandar ynviar el su montanero para que vea dónde más buenamente se puedan hacer». AHN. Clero. Legajo 1295.

42 Pérez-Embid Wamba, Javier. «Deforestación y reforestación en Sierra Morena occidental (siglos XIII-XVI)». En Clemente Ramos, Julián. El medio natural en la España medieval. Cáceres, 2001, pp. 451-475.

43 La recogida selectiva de la leńa seca de los bosques es una práctica tradicional que permite la «limpieza» del monte y evita, o reduce, la posible propagación y/o proliferación de incendios forestales. Sin embargo, en el interrogatorio a los testigos de la pesquisa entre Bentretea y Terminón, en 1454, se insta a "que averigüen quienes quemaron los montes del abad». Ruiz Gómez, Las formas del poblamiento rural, doc. 207, p. 1529.

44 "Dixo que en estos montes e términos que dicho ha que seyendo moço en poder de su padre e aún después sobre sí que este testigo fiso carbón en el monte de Ventrytea commo desyende de la tyerra de Salas fasta el dicho logar de Bentretea e que abenían el dicho carbón con los de Ventrytea e les daban çierta cosa porque les dexasen sacar el dicho carbón; e esto que lo fasían desde la Nava de Ventretea fasta Fuente Padierna". AHN. Clero. Carpeta 325, doc. 13.

45 Corullón Paredes, Isabel y Escalona Monge, Julio. «Entre los usos comunitarios y la iniciativa seńorial: la producción de hierro en el valle de Valdelaguna (Burgos) en la Edad Media». En Bolós, Jordi. Estudiar i gestionar el paisatge històric medieval. Lleida, 2007, pp. 39-81.

46 1500, abril, 13. Oña: «Otrosí que no puedan faser carbón en los dichos sus montes de La Horadada salvo lo que ovieren menester los vecinos del dicho logar sus vasallos (Tártales de Cilla) para dar al herrero de Trespaderne para labrar sus herramientas dellos e non para otra cosa so pena de seysçientos mrs. para su cámara del dicho señor abad». AHN. Clero. Legajo 1295.

47 Ruiz Gómez, Las formas del poblamiento rural, p. 1353. 
FRANCISCO REYES TÉLLEZ Y GONZALO VIÑUALES FERREIRO

PAISAJE FORESTAL Y REPRESENTACIÓN SOCIAL EN CASTILLA (SIGLOS XIV-XVI). LOS MONTES DE SAN SALVADOR DE OÑA (BURGOS)

\subsection{Interpretación del paisaje forestal: la toponimia}

La fase de interpretación es entendida por Londońo y Gómez Alzate como la de la percepción visual del mismo a escala humana cuya conexión con nuestro análisis del paisaje forestal está focalizada específicamente en la denominación de los lugares o elementos que conforman la realidad geográfica del paisaje, fundamentalmente la toponimia, que es considerada por algunos autores como una «cartografía mental» del territorio. Existe un acuerdo más o menos unánime en aceptar el valor y la significación de los topónimos como fuente ${ }^{48}$, aunque también existe, de manera más o menos global, una conciencia colectiva que considera que estas referencias no permiten reconstruir de manera plenamente fidedigna el paisaje original expresado en los textos.

La presencia de topónimos es relativamente escasa en la documentación judicial analizada ${ }^{49}$. Todos ellos gozan de un carácter descriptivo bastante general, pues lo que abunda es la enumeración o la referencia a poblaciones o localidades sin más datos añadidos o información complementaria. Los términos que aluden a poblaciones, villas, etc., se presentan generalmente bajo la misma construcción o la misma voz. No aparecen ni se indican con nombres o denominaciones diferentes que pudieran recalcar una forma de llamarlo más antigua, más clásica, tradicional o heredada, o que le aporte un valor simbólico ańadido a ese topónimo. Da la impresión de que para el procedimiento judicial es escasamente relevante una sobre acumulación de datos geográficos, ya que lo que está en discusión no es el territorio sino su uso o propiedad. De esta manera poco importan posibles errores de transcripción o matices en la descripción de los paisajes. En el pleito seguido con los vecinos de Arroyuelo (1499 y 1500), hay dos documentos muy seguidos cronológicamente pero en cuya descripción hallamos ligeras modificaciones:

(1) «Avían tenido y tenían uso e costumbre e servidumbre e derecho de cortar e traer leńa e horcas e horquillas e otra manera nesçesaria del monte desde el camino del limón e sube a la lobera e a sumo de Val de Vinuelas e a la hera del limón e desde por el çerro para adelante fasta el alverguería; e aquello estava así declarado y mandado por sentençia definitiva e por los dichos sus partes usado e guardado e acostumbrado e de tiempo antyguo ynmemorial acá en vista e sabiduría e con consentimiento de los señores del dicho monte e término». 1499, junio, 28. (ARCHV, Registro de Ejecutorias, 134, 41).

(2) «Avían tenido e tenían uso e costumbre e servidumbre e derecho de cortar e traer leña e horcas e horquillas e otra madera nesçesaria del monte desde el camino del limón e sale a la lobera e ha sumo de Val de Vinuelas e a la hera del limón e descende por el çerro adelante fasta el alverguería e aquello estaba así declarado» 1500, julio, 28. (ARCHV, Registro de Ejecutorias, 149, 1).

48 «En los topónimos cristaliza este encuentro de espacios y tiempos: el nombre dado a los parajes los eleva culturalmente, y los socializa, haciéndolos salir de su anonimato e introduciéndolos en la memoria y en la historia». Riesco Chueca, Pascual. «Nombres en el paisaje: la toponimia, fuentes de conocimiento y aprecio del territorio». Cuadernos Geográficos, 2010-2011, vol. 46, p. 11.

49 Sobre la toponimia de Ońa y su tierra, véase: Rojo Díez, Eduardo. «Toponimia actual e histórica de Ońa y Tamayo». En Rojo Díez, Eduardo. Oña y su monasterio en el pasado de Castilla. Historia, cultura y toponimia. Oña, 2009, pp. 179-238. 
FRANCISCO REYES TÉLLEZ Y GONZALO VIÑUALES FERREIRO PAISAJE FORESTAL Y REPRESENTACIÓN SOCIAL EN CASTILLA (SIGLOS XIV-XVI). LOS MONTES DE SAN SALVADOR DE OÑA (BURGOS)

Por otra parte, si detallamos el cómputo de topónimos identificado en el conjunto de la documentación examinada, observamos que un sesenta por ciento de ellos aluden a fenómenos de carácter medioambiental como peñas, ríos, lomas, flora y fauna, etc., frente a un cuarenta por ciento relativos a factores antrópicos (fazas, mojones, cruces, etc.). Algunos elementos responden a usos del suelo y otros a delimitaciones específicas (mojones) que no tienen otra finalidad expresa. Esta circunstancia enlaza con la idea de que son los elementos culturales los que ofrecen mejor la foto fija que guarda en su memoria una persona o un grupo de personas, a pesar de que puedan abundar (o no) las alusiones a fenómenos naturales ${ }^{50}$. En la sentencia arbitral dictada entre el monasterio de Ońa y la villa de Tamayo sobre corta y roza de una parte de la sierra de Tamayo (9 de mayo de 1467), al delimitarse los mojones, se insiste en la nomenclatura de aspectos culturales (17) frente a los ambientales (solo 8) ${ }^{51}$. Podríamos preguntarnos si la mayor o menor presencia de conceptos relacionados con la naturaleza y el terreno, las vías de comunicación, los cruces de caminos, etc., en los términos usados para describir el territorio estaría más en consonancia con la percepción que tendrían los habitantes de las localidades circundantes a esos espacios, en sus usos y paseos cotidianos por su entorno, y si, por el contrario, las alusiones a elementos culturales, de mayor contenido simbólico, responderían más a la interpretación que de ese espacio tiene el propio monasterio de Ońa.

Describir conlleva elegir, seleccionar del contexto sitios o referencias frente a otros, concediéndoles mayor importancia bien por el peso de la memoria o del pasado, bien porque está dotado de mayor importancia o se le quiere traspasar, dotar esa relevancia, ignorando otros presentes pero carentes de atención para el que los visualiza. Esta apreciación se puede comprobar con cierta prudencia en las delimitaciones de términos o heredades ${ }^{52}$. Cuando se indican los mojones que circunscriben un espacio, se alude con mayor frecuencia a elementos simbólicos culturales de cariz religioso y menos a accidentes naturales $^{53}$. Fijémonos en la delimitación de los términos que se recoge en la

50 «El territorio y sus posibilidades de movilidad y amplitud visual ofrecen una experiencia espacial y temporal, en la que la densidad de los elementos ambientales naturales adquiere mayor importancia que la densidad de los elementos culturales, siendo estos últimos, a pesar de su baja intensidad, los que posibilitan su apreciación visual, su apropiación espacial y, por tanto, su dominio territorial». En Gómez Alzate y LoNDOÑo López, Paisajes y nuevos territorios, p. 32.

51 "Que se ponga un moxón en una faza de Martín García, clérigo, que es junto cabe Valderrodrigo fasta Tamayo. E dende arriba otro moxón que está en una peña, que está junto con Valderrodrigo fasta Tamayo. E dende arriba, a otro moxón que está encima del cumbre de la sierra, cerca del camino que va de calleja a la cima de la sierra. E dende adelante, el cumbre, el cumbre de la dicha sierra arriba hasta Peńa Flecha, donde está otro moxón en un peńasco que está una cruz en él. E dende abaxo, como atraviesa a un peńasco vermejo, que está encima del calero que ficieron los de Ońa. E dende abaxo, al camino que viene de Rebollar a Tamayo a otro moxón que está entre la Fuente Muño, e de otra fuente que está en otra heredad del monasterio de Ońa. E dende adelante por el camino que va fasta Tamayo, a una encrucixada de los caminos, que va el uno al callejo e si otro a la dehesa de Tamayo. E dende, derecho al dicho moxón primero que está en la dicha heredad de Martín García, clérigo cabe Valderrodrigo». Vid. Ruiz Gómez, Las formas del poblamiento rural, p. 1621.

52 Bonaudo de Magnani ya precisaba que no existía en el entorno de Ońa la tradición de indicar linderos mediante setos, cercas o vallados, sino que lo habitual era hacerlo con mojones o estacas (de madera). Bonaudo de Magnani, «El monaserio de San Salvador de Oña», p. 56.

53 «Et que aunque sabe que vyo que los de Salas enbyaron requerir a los de Bentrytea a que saliesen a apear los términos que son entre los dichos conçejos de Salas y Ventrytea, et a renovar las cruçes antiguas que parten los términos entre dichos conçejos». Ruiz Gómez, Las formas del poblamiento rural, p. 1531. 
sentencia arbitral entre el concejo de Penches y el de Ońa en 16 de febrero de $1454^{54}$, o en la sentencia arbitral entre el concejo de Tamayo y el monasterio de Ońa en 9 de mayo de $1467^{55}$. Parece que al monasterio le interesa tener unas referencias muy bien identificables a la hora de precisar los límites de sus espacios. No está tan interesado en el terreno como en el producto del terreno.

En este punto nos parece interesante insistir en lo que Pascual Riesco ha dado en llamar "denominaciones efímeras», aquellas que nunca se llegaron a registrar por escrito y que plasmarían un tipo de representación social del paisaje que nunca se podrá visualizar en la documentación puesto que se verbalizan pero no se redactan ${ }^{56}$. Muchas de ellas responderían razonablemente a esas marcas, esos espacios o lugares que solamente aquellos que lo transitaran con asiduidad podían conocer y compartir con sus convecinos gracias a un conocimiento muy próximo y cotidiano, cercano, habitual y vivido del terreno.

De acuerdo a la documentación analizada el porcentaje de aparición de topónimos solamente se incrementa razonablemente en las pesquisas con interrogatorio a los testigos. Obsérvese en el caso de la pesquisa entre Bentretea y Terminón en 1454:

Está presente Ferránd Sánchez de Vañuelos, alcaide de la fortaleza de Vriviesca, jues dado por la señora condesa de Haro en un debate que es entre el seńor abad de Ońa y el conçejo del su lugar de Bentretea de la una parte e el conçejo del dicho lugar de Terminón de la otra parte, que es sobre çiertos términos, paresçió y presente Juan Sánchez Çurrylla vesino de Nofuentes procurador que es del dicho señor Abad [...] sobre rasón de çiertos términos que son entre los dichos conçejos en debate que se llama la dehesa de Ventretea commo sale la dehesa al lomo de verriela a la peńa el gallo e viene al vallejo e baxa al maçullo de sant Bartolomé de Quintanar e commo sale al lomano de Valdetoria e sale por allí arriba a Peńa Águila e dende a la Peńa de Granno e commo avaxa a las eras de Salas e va por ende a Fuente Padierna e a la Torca de Val de Oria e al canto de Çaraçuela ${ }^{57}$.

En 1320 se registran 7 testigos en la pesquisa efectuada por el monasterio de San Salvador de Ońa sobre el uso y aprovechamiento de los montes de la hospedería por

54 «De cómo toma el vallejo de Piedra Hita, como vyene el camino de Frías a Ońa, por el camino adelante fasta çerca la yglesia de Santo Venan, do está un mojón e una cruz en él. E dende a ençima de la salçera detrás de la yglesia de Santo Venan, do está una cruz en una peńa. E dende por el cumbre de la sierra adelante a ençima del vallejo de Ornillos, do está un mojón. E dende por el dicho vallejo ayuso, debaxo del camino que va de Fría a Oña, a una peña que está una cruz en ella». Ruiz Gómez, Las formas del poblamiento rural, pp. 1535 y ss.

55 «Del dicho moxón de cima de la cumbre de en derecho de Valderrodrigo, como va el cumbre de la sierra cabe el camino que sube al vallejo. E dende, la sierra ayuso a dicho moxón que está abaxo de la heria, cabe el ayalejo, en que está una cruz». Ruiz Gómez, Las formas del poblamiento rural, pp. 1613 y ss.

56 «Es probable que existiera una capa de denominaciones efímeras, creadas por un estrato social muy humilde, formado por carboneros, cazadores, corcheros, colmeneros, cabreros, porqueros y serradores. Esta población flotante, generalmente asentada en chozas itinerantes y en majadas, tendría sin duda su propio repertorio de denominaciones. Infelizmente, estos topónimos internos apenas han dejado huella escrita en apeos, testamentos o registros de hacienda, porque no ofrecían interés como elemento de deslinde o identificación, al ser toda la propiedad o bien comunal (proindivisa) o bien de un solo dueño». Ruiz Gómez, Las aldeas castellanas, p. 12.

57 AHN. Clero. Carpeta 325, doc. 13. 
FRANCISCO REYES TÉLLEZ Y GONZALO VIÑUALES FERREIRO PAISAJE FORESTAL Y REPRESENTACIÓN SOCIAL EN CASTILLA (SIGLOS XIV-XVI). LOS MONTES DE SAN SALVADOR DE OÑA (BURGOS)

parte de los concejos de Arroyuelo y Villapanillo. En la descripción que presenta el abad de Ońa, don García, se delimitan los términos: «que usaran ellos de taiar en los nuestros montes que son sobre el aluerguería, commo parte el camino del Limón que sube a la Lobera e va a somo de Valdevinnuelas e al era del Limón». No obstante, los testigos presentan añadidos interesantes sobre la toponimia o descripción del paisaje. Martín Pérez de Villadeveo precisa, «de commo toma la puente del aluerguería» y "al era del Limón dende fasta el Ebro»; Martín García de Sante agrega en su testimonio, «de la torca de la Lovera e va al era del Limón», y «al era de somo el Limón e sube a las pennas de somo la penna de Val de Datiles». Pero Alfonso de Fontanizo incorpora algún dato más, «e al era del Limón dende por el çerro adelante fasta el alberguería».

Es cierto, que esas menciones aluden a la propiedad y, por tanto, a la perduración de un sistema de gestión y control, pero puede no querer, o no deber, cambiarse. Sin embargo, queda anulado ese carácter dinámico. Conectaríamos aquí con la idea de pensar en "paisajes no visibles», aquellos que permanecen en el recuerdo. En la pesquisa entre Bentretea y Terminón del año 1454, los testigos son preguntados si coinciden en la descripción de los apeos o heredamientos y sus linderos; uno de los testigos, Juan del Río, contesta de la siguiente manera: «Dixo que sabe donde diçen la peńa de Granno e a las cruçes e a Fuente Padierna e el canto de Çaraçuelo e lo otro que no lo sabes ${ }^{58}$. Conviene recordar que la identificación de un paisaje lleva ya implícita, o supone, la intervención humana sobre el mismo. Y en la pesquisa sobre el uso de los montes de la Hospedería, entre Arroyuelo y Villapanillo y el monasterio de San Salvador de Ońa, en abril de 1320, encontramos cómo uno de los testigos, "Garçy Rodríguez de Fontanizo, iurado e preguntado, dixo sobre la iura que él naciera en lalverguería e criara y, e que viera a los de Arroyuelo taiar e llevar del monte" "59. Si comparamos la descripción de los términos que se recoge en ese documento con las que se realizan por motivos semejantes en los pleitos de 1499 y 1500 , observaremos que la presentación que se hace de los linderos es casi idéntica. El monasterio y sus procuradores van a tomar la descripción recogida en la documentación anterior (justamente la de 1320) como la jurídicamente fiable, sin procurar confirmar si la extensión de esos límites o su demarcación correspondía efectivamente con aquella.

El lenguaje empleado en la redacción de los textos puede tener mucho de estereotipado. No es este el escenario para debatir acerca de la idoneidad o incluso del valor de la documentación jurídica como fuente para el tema que nos ocupa ${ }^{60}$. Siguiendo

58 AHN. Clero. Carpeta 325, doc. 13.

59 Oceja Gonzalo, Documentación del monasterio de San Salvador de Oña (1319-1350), p. 16.

60 «No menos problemático es el proceso de construcción de la propia fuente. De hecho, existe una viva polémica acerca del estatuto del proceso jurídico como fuente para el historiador, que se deriva de la propia construcción jurídica del objeto que se asocia a la entrada de un conflicto en el campo jurídico. En última instancia, de lo que se trata es de determinar, si los pleitos en general y muy particularmente los testimonios que los acompañan, constituyen un tipo de fuente que nos permite estudiar únicamente el tipo de relaciones que se inscriben en el texto y que el propio pleito ayuda a construir o si por el contrario esta documentación nos permite el análisis de relaciones extratextuales, esto es, de contextos y prácticas exteriores a la propia operación de construcción de la fuente». Oliva Herrer, Hipólito Rafael. «La memoria fronteriza. Memoria histórica campesina a fines de la Edad Media». En Fernández de Larrea, Jon Andoni y Díaz de Durana, José Ramón. Memoria e Historia. Utilización politica en la Corona de Castilla al final de la Edad Media. Madrid, 2010, pp. 255-256. 
la opinión de Oliva Herrer, coincidimos en pensar que esa documentación puede ofrecer valiosas aportaciones extratextuales, aunque somos conscientes de que la redacción de muchos de los documentos puede estar, y en bastantes ocasiones está fundamentada, en un discurso erudito y formulativizado, configurado en la mente del notario, plasmado a través de la pluma del escribano, y que solamente de manera muy lenta va evolucionando, generando nuevas fórmulas, procedimiento, expresiones y jerga. Además, en muchos casos la repetición exacta de modismos, frases o del cuerpo del texto completo se debe a que se reitera esa o esas fórmulas jurídicas porque se considera que esa es la vía para mantener la fiabilidad del contenido, pues si se cambia o se reformula se puede desvirtuar el valor legal original. Además, hay muy pocos documentos que incluyan el testimonio de testigos que pudieran expresarse de una manera más abierta y espontánea.

$\mathrm{Si}$ revisamos los topónimos que se señalan en los documentos, se constata una intensa pervivencia de los nombres fijados en el espacio. Da la impresión de que monasterio y concejos no han modificado en ese lapso de tiempo la imagen fija que reciben de sus montes, pues el paisaje no se discute, ni generalmente se precisan nuevos términos. Los escasos cambios detectados parece que responden más a pequeños errores de transcripción en la lectura de los documentos por parte de los escribanos que no en la visión del conjunto de la población. Así en relación con la villa de Arroyuelo encontramos que se repiten los mismos linderos en 1499 que en 1320. Se observa por tanto, una gran pervivencia en cuanto a la percepción de límites, vías de acceso, caminos, hitos, etc., pero con un ligero incremento de la competencia.

\subsection{Valoración del paisaje forestal: la representación social}

La tercera fase del planteamiento metodológico corresponde al análisis de la valoración del paisaje a través de su representación social. Nuestro objetivo ha consistido en tratar de entresacar a partir de algunos casos concretos de la documentación presentada cuáles pudieron ser las representaciones sociales que tenía cada uno de los agentes o actores implicados en los diversos pleitos o disputas acerca del uso y aprovechamiento de los bosques. La raíz de esa conflictividad podría estar ubicada en la pertinente distinción que establece Echavarren entre las diferentes interpretaciones de la definición de lugar natural y su posible transformación en icono natural ${ }^{61}$. Partiendo de lo que entiende por lugar natural - «un espacio histórico, relacional e identificatorio, un espacio personalizado, con vida social, particular, y caracterizado por una alta función social»-, expone que las comunidades locales gestionan y controlan sus propias definiciones y significados del espacio (interpretado siempre por el grupo como lugar natural) lo que conlleva un natural sentimiento de pertenencia a un paisaje. Pero, si la comunidad pierde el control de ese espacio y de su definición, estará viendo mermado su control simbólico del mismo. Este déficit suele venir ocasionado por la intervención de agentes ajenos o «intrusivos» que van a gestionar el significado de ese espacio pero transformándolo en

61 Echavarren, José Manuel. «Conceptos para una sociología del paisaje». Papers, 2010, vol. 95/4, pp. 1117-1118. 
FRANCISCO REYES TÉLLEZ Y GONZALO VIÑUALES FERREIRO PAISAJE FORESTAL Y REPRESENTACIÓN SOCIAL EN CASTILLA (SIGLOS XIV-XVI). LOS MONTES DE SAN SALVADOR DE OÑA (BURGOS)

muchas ocasiones en icono natural, «que constituye una interpretación del territorio donde las personas se relacionan con el símbolo en lugar de con el territorio», y que se expresa generalmente en un conflicto de significados centrados en aspectos como la citada definición del espacio, los derechos de uso de esos recursos ${ }^{62}$, los propios usos y aprovechamientos de esos recursos, la propiedad de los mismos y las decisiones gestoras sobre esos recursos.

La idea de representación social del paisaje va unida a dos conceptos clave: los de memoria e identidad. Bajo la consideración de que el paisaje o los paisajes son objetos de estudio histórico, habremos de entender que los paisajes están vinculados a la memoria ${ }^{63}$. La memoria está indisolublemente unida a los paisajes, no solo como percepción visual, sino también como conocimiento, pues, siguiendo postulados constructivistas, estaremos de acuerdo en la máxima de que los individuos (la/s persona/s) «ven lo que saben», y que son los mecanismos lingüísticos y textuales los que proyectan nuestra percepción del paisaje en nuestro contexto social y cultural, dándole forma o creándolo como una realidad. Una realidad tangible, además de la del conocimiento, que es la ubicación y la orientación. Y tiene una cierta continuidad: los paisajes del pasado siguen reflejándose en los paisajes del presente, pues la memoria nos permite así poder ver aquellos paisajes que queremos, que deseamos ver, de acuerdo a nuestra propia idea construida socialmente de paisaje condicionada por nuestra manera de aprehender el territorio. Con certeras palabras lo expresaba Simón Schama: «el paisaje es el trabajo de nuestra mente. Este escenario está construido mucho más por estratos de memoria que por capas de roca» ${ }^{64}$.

En relación con la memoria de los paisajes hemos de partir del supuesto de que existe un conjunto de representaciones sociales de ese paisaje que pueden ser anteriores y por tanto muy útiles para poder articular y comprender los procesos de tensión o conflicto por el uso de montes y bosques. Esto es, sin representación social del paisaje no puede darse el conflicto, pues es previa a este ${ }^{65}$. Esta socialización del paisaje suele ser idealizada o estilizada y se proyecta en el imaginario colectivo de un grupo social, el cual en su propia construcción de memoria va a generar un modelo, una simbolización común. Un paisaje, o unos paisajes, que se han fosilizado como verdaderos arquetipos (los denominados por Nogué "paisajes de referencia»), pero que pueden ser singularmente distintos a los paisajes reales, a los paisajes vividos por la población ${ }^{66}$. En una gran mayoría de las ocasiones, cuando queda recogido en la documentación (portadora

62 «No debe resultar extraño, por tanto, que su explotación fuera objeto de innumerables conflictos que se planteaban a diferentes niveles, desde la definición del régimen de aprovechamientos en el interior de las comunidades campesinas del entorno, a los enfrentamientos de intereses divergentes que oponían a los habitantes de las comarcas con los nobles representados en la zona, en un espacio fuertemente señorializado». Oliva Herrer, Hipólito Rafael. «El aprovechamiento del monte en Tierra de Campos a fines de la Edad Media». Cuadernos de la Sociedad Española de Ciencias Forestales, 2003, vol. 16, pp. 201-206.

63 Verdier, Nicolás. «La memoria de los lugares: entre espacios de la Historia y territorios de la Geografía». En Ortega Cantero, Nicolás; García Alvarez, Jacobo y Mollá Ruiz-Gómez, Manuel (eds.). Lenguajes y visiones del paisaje y del territorio. Madrid, 2010, pp. 209-219.

64 Sснамa, Simón. Landscape and memory. New York, 1995, pp. 6-7.

65 «Un conjunto de representaciones sociales, de las que dependen los conflictos y luchas de apropiación del espacio». Gómez Zotano y Riesco Chueca, Marco conceptual y metodológico para los paisajes, p. 89.

${ }_{66}$ NoguÉ, Joan. «El retorno al paisaje». Enrahonar, 2010, vol. 45, pp. 130-131. 
asimismo de memoria social), esta en su lenguaje suele contradecir el carácter dinámico, por ecológico y por antrópico al mismo tiempo, del paisaje. Y tiende a aparecer referenciada en los textos mediante la expresión recurrente de que memoria de omes no es en contrario, que aunque alude a los usos y propiedad, perpetúa un paisaje que ha podido modificar, y mucho, sus características ecológicas ${ }^{67}$. En otros ejemplos textuales, esta reiteración no pretende sino transmitir una secuencia de un uso inmemorial, de carácter tradicional y comunal, como en el caso siguiente, en el que empleando la década como cantidad reconocible por todos los agentes que intervienen y/o escuchan, y repitiendo la serie hasta alcanzar la cifra considerada suficiente de los sesenta años, «dixieron e recontaron que ellos estando en posesión de paçer las yervas y bever las aguas e comer la grana con sus ganados mayores e menores en la dehesa que llaman el ensynal de Urría que es entre amos los dichos lugares Mixangos y Urría de diez e de veinte e de treinta e de quarenta e de cincuenta e de sesenta ańos a esta parte e de tanto tiempo que memoria de omes no era en contrario ${ }^{68}$. No entraría a formar parte de este simbólico ni la apreciación estética del paisaje ni la emotividad o la nostalgia, presente en otros contextos contemporáneos ${ }^{69}$.

Y es que el paisaje puede convertirse en soporte de la identidad siempre y cuando refleje y se comporte como un elemento simbólico del grupo que comparte interpretaciones y valoraciones del mismo ${ }^{70}$. Para ello parece necesario, o quizá, imprescindible, que exista tanto una conciencia como una mirada de "exclusividad", que englobe y asimismo aísle ese espacio para que solamente pueda ser descifrado participando de un mismo código simbólico. En un artículo reciente se ha presentado, bajo el telón de fondo del bicentenario de la independencia de México, el valor identitario de algunos paisajes (históricos) que han impactado en la construcción del citado país ${ }^{71}$. Y cuando Nicolás Ortega reflexiona sobre la autorizada figura de P. Vidal de la Blache y su Tableau de la Géographie de la France expone que «el paisaje se vio así directamente conectado con los procesos de conformación de la memoria histórica y de la identidad nacional. Entender el paisaje, comprender lo que paisaje es y significa, acercarse a sus cualidades y a sus valores, puede ser de esta manera un camino para formar la conciencia histórica y la conciencia nacional $»^{72}$.

67 Jara Fuente, José Antonio. “Que memoria de onbre non es en contrario”. Usurpación de tierras y manipulación del pasado en la Castilla urbana del siglo Xv». Studia Historica. Historia Medieval, 2002-2003, vol. 20-21, pp. 73-104.

68 AHN. Clero. Legajo 1214. 1422, agosto, 7. Mixangos. Va inserto en 1474, agosto, 13. Ońa.

69 Pereda Feliú, Vladimir y Cortés Estay, Leonardo. «Autopistas elevadas y resistencia ciudadana: imaginarios e intolerancia en torno a las obras de infraestructura vial». DU\&P. Revista de Diseño Urbano y Paisaje, 2011, vol. VIII, n. ${ }^{\circ} 21$.

70 Zapiain Aizpuru, M. ${ }^{a}$ Teresa. «Reflexiones identitarias en el territorio contemporáneo. La construcción colectiva de lugar. Caso de estudio de la Vega de Granada». Cuadernos Geográficos, 2011, vol. 48, pp. 79-108.

71 Thiébaut, Virgine. «Paisajes identitarios en México. Análisis y valoración de paisajes de la independencia». Estudios Geográficos, 2011, vol. LXXII, n. ${ }^{\circ} 271$, pp. 655-680.

72 Ortega Cantero, Nicolás. «Paisaje, Historia y Nación. (A propósito del Tableau de la géographie de la France de Paul Vidal de la Blache)». En Ortega Cantero, Nicolás (ed.). Paisaje, memoria histórica e identidad nacional. Madrid, 2005, p. 10. 
FRANCISCO REYES TÉLLEZ Y GONZALO VIÑUALES FERREIRO PAISAJE FORESTAL Y REPRESENTACIÓN SOCIAL EN CASTILLA (SIGLOS XIV-XVI). LOS MONTES DE SAN SALVADOR DE OÑA (BURGOS)

Pero, frente a la postura expresada abiertamente por los concejos, también el monasterio de San Salvador de Ońa argumenta con su memoria. En los documentos en los que esto aparece consignado, el monasterio asienta su memoria de uso mediante la norma jurídica, al esgrimir sus derechos a través de documentación pretérita que le garantiza legalmente su propiedad. Fijémonos en primer lugar en un documento de 1724. Dentro de los papeles relativos a un pleito con la villa de Herrera se inserta una consulta para ver si el abad de Ońa podría dar permiso para cortar ciertos pinos en los montes comuneros. Y para argumentar su causa recurren a la mención de diversos y selectivos documentos anteriores. ¿A cuáles recurren? Primero, a la donación que hizo el conde don Sancho de la villa de Oña cum montibus paludibus en el año 961, «el qual privilegio con otros de los Reies que lo confirman y añaden más exemplos», y que han sido confirmados por Felipe V en 1708. Segundo, el privilegio del rey Sancho II en el que concede «licencia al abad para poblar en sus lugares en cuia execuzión se pobló la villa, que devía de estar desierta». Tercero, del ańo 1190, en el que el abad don Pedro de la Calzada concedió su fuero a la villa de Oña. Y cuarto, el que más nos atañe, la concordia que se fijó en 1452 para que los vecinos de Ońa puedan cortar y pacer en todos los montes comuneros ${ }^{73}$. Se alude a tres momentos previos de enorme importancia y significación: aquellos que les han dotado de derechos para ser beneficiarios del uso y aprovechamiento de esos montes. En otro de los litigios, el que se mantiene con el concejo de Soto por los montes de Piedralada y Domingo Sancho, con fecha de 9 de mayo de 1394 se detalla que:

el dicho seńor abad dixo que, como al dicho su monesterio fuera fecha donaçión e limosna por çiertos señores Reyes e otros señores e señoras de Castilla a quien Dios dé santo paraíso de los montes e términos que llaman de Piedralada e de Domingo Sancho muy grandes tiempos abía, segund se contenía por los privilegios que de los dichos montes al dicho monesterio fueran dados, de los quales dichos privilegios e cartas rodadas e plomadas mostró ante nos los dichos escribanos e testigos ${ }^{74}$.

En relación con el concejo de Soto tenemos noticias de los montes de Piedralada y Domingo Sancho desde 1340. En 24 de mayo de ese año la viuda de Ruy Pérez de Soto, doña Teresa, devuelve la guarda de dichos montes a San Salvador de Oña, pues los había tenido en guarda por mandado del monasterio evitando que nadie entrara a cortar madera. Sin embargo, en 1455 se desarrolla un pleito por su uso en el que se incluye información

73 «Y llegado el ańo de 452 en que andaba el monasterio con muchos pleitos domésticos y era abad Fray Juan de Roa, que era fijo de Valladolid, de los reformadores, y poco actuado de las cosas de Oña pasaron a hacer una concordia en cuya cabeza se relaciona cómo el abbad Don Pedro dio montes a los vezinos para que se pudiesen mantener y sostener y se dispone que todos los montes assí los que tenía el monasterio confinantes con los lugares comarcanos como los que tenía la villa por el Abad Don Pedro sean comuneros para el cortar y pacer, donde se expresa pueda el Abad hazer gracia de cortar madera y leña en los Montes de la Sierra que dizen la mesa del Abbad y Montes de la Horadada: y reservó el monasterio para sí los Montes de Sante y en capítulo 5 se dispone que el abad pueda mandar cortar en todos los montes la madera que hubiere menester para sus casas sin lo consultar con la villa (subrayado en original) que es el casso presente, pues el corte de los quatro pinos era para unos trillos para la casa. Y los vecinos puedan cortar para sus casas, a determinazión de los alcaldes pero no para bender. Y en el capítulo 6 se declara quedar el abbad y monasterio con el señorío y propiedad de todos los montes, como verdaderos señores de ellos. En el capítulo 7 se dize que quando algún Monte o montes se hubieren de cotear y guardar sea con acuerdo del Abbad». AHN. Clero. Legajo 1295.

74 AHN. Clero. Legajo 1214. 
diversa: la sentencia dada en Sahagún, etc. Aún en 1464 se presentó una probanza contra los concejos de Soto, Quintanilla y Quintana Vélez para demostrar que los montes de Piedralada pertenecían al monasterio. De todos ellos nos interesa la información que se incluye en el documento de 1455, pues es la única referencia que hemos localizado en relación a una perambulación de los montes y términos ${ }^{75}$. Sabemos por él que, el sábado 9 de mayo del año 1394, el abad del monasterio benedictino de San Salvador de Oña, don Sancho, llevó a cabo una visita a los montes y términos de los concejos de Piedralada y Domingo Sancho, acompañado de merinos, escribanos y mozos, con la pretensión de revisar los linderos de sus propiedades, definirlos, dejar constancia de quién tenía la posesión de los mismos de acuerdo a los privilegios que así se la habían otorgado y, tras esta comprobación, hacer merced a los concejos para que pudieran entrar y aprovecharse de los montes:

E que continuando el señorío e tenencia e posesión de los dichos sus montes que entrava e entró en ellos e los apeava e apeó de commo toma de Barsina e va por el lugar del Aldea e sale derecho al Portillo de Busto por el camino Real que es entre Xagardex [Zagández] e el dicho logar del Aldea e commo va del dicho Portillo por çima a la syerra al castillo de Piedralada e va derecho por ençima la syerra fasta Penches. E bien de allí dixo que apeava e usava del dicho su seńorío e posesión de todo lo otro según se contenía por los dichos previllejos, e que protestava que no le fuese perjuisio porque non lo apeava todo porque era muy gran término e se enojaría de los andar, mas que a salvo le quedase de lo apear todo tiempo quando podiese o quisiese e fuese su merçed ${ }^{76}$.

¿Podría tener alguna conexión este recorrido con la mención en un documento del ańo 1111, en el que Alfonso I dona ciertas propiedades al monasterio de San Juan de Entrepeñas: «concedimus etiam ut homines de ipso monasterio, habeant ligna et herbas, et pasturas et aquas, et introitum et exitum, per totos illos montes qui sunt in circuito de Petralata»? ${ }^{77}$. No en la idea de un circuito, un camino, sino una delimitación mental de los alrededores del castillo, por donde razonablemente podrían transitar los linderos conocidos y aceptados por la colectividad.

Según nos relata el documento, el paseo es largo y cansado, y el abad decide hacer una parada para comer: "e este día estando el dicho señor abad comiendo ensomo la dicha syerra al Portillo que disen de Soto en una choça grande derramada de los dichos sus montes que allí feo faser a sus omes al pié del dicho castillo en su compaña». Para el abad y para el monasterio, y para todo el séquito que le sirve, la referencia esencial en esta perambulación es la fortaleza de Petralata; es el hito clave en su contextualización de todo ese entorno, reflejo de su señorío, de su fuerza y autoridad. Tanto es así, que una vez allí cierra esa perambulación, se siente cómodo y con el recorrido completo, no necesita seguir recorriendo ni caminando esos espacios, pues su poder está consolidado ${ }^{78}$.

75 Como podemos comprobar, el recurso al recorrido de los caminos para resolver litigios no era excepcional: «ambulaverunt per pedem terminum antiquum secundam regulam». Álamo, Colección diplomática, doc. 319, año 1199.

76 AHN. Clero. Legajo 1214.

77 Álamo, Colección diplomática, doc. 138, año 1111, p. 168.

78 «El dicho señor abad estobo ay con su compańa e testigos e nos los dichos escribanos e merino comiendo e folgando todo el dia fasta bien tarde que se fue porque era sábado por noche a su monasterio". AHN. Clero. Legajo. 1214. 
FRANCISCO REYES TÉLLEZ Y GONZALO VIÑUALES FERREIRO PAISAJE FORESTAL Y REPRESENTACIÓN SOCIAL EN CASTILLA (SIGLOS XIV-XVI). LOS MONTES DE SAN SALVADOR DE OÑA (BURGOS)

Es razonable, por tanto, que el castillo de Petralata fuera un referente perfectamente válido de un paisaje cultural compartido por todos los presentes, y también por sus representados $^{79}$. En ese mismo desarrollo del relato el escribano anota en el párrafo del documento que precede al anterior que «mandaba e mandó a los sus reposteros e cosineros que le guisasen de comer al pié del dicho su castillo de Piedralada e a ojo de Burueba». ¿Podríamos conectar la frase "e a ojo de Burueba» con el concepto geográfico de «cuenca visual» en el estudio del paisaje? Gonzalo Tévar entiende por cuenca visual «el conjunto de superficies o zonas que son vistas desde un punto de observación, o dicho de otra manera, es el entorno visual de un punto» ${ }^{80}$, mientras que Rafael Escribano y José Eugenio Martínez hablan de este vocablo identificándolo con el de unidad visual del paisaje y lo definen como «una síntesis de las condiciones físicas del territorio que recoge información de los puntos visibles y no visibles de acuerdo con la pendiente de una recta imaginaria que se establece desde un punto significativo del terreno» ${ }^{81}$. En este caso el escribano está consignando una percepción individual, probablemente de origen estético pues es una contemplación, pero que está cargada de objetividad, pues es una proyección visual que es la forma más habitual y mensurable de percibir el paisaje. Y que además al trasladarse al papel se dota de un valor cultural. No se trata de rastrear datos de aspectos relativos a la calidad o fragilidad del paisaje, pero sí de constatar la definición de una unidad irregular de paisaje que viene marcada por un punto neurálgico de observación, situado en una cota complementaria de visibilidad como es la fortaleza de Piedralada.

Nos encontramos ante una situación dialéctica, pues confluyen dos interpretaciones distintas del entorno natural y su construcción cultural. La memoria expresada por los concejos radica en la idea de que han podido disfrutar de la explotación de los montes de manera continuada y sin intromisiones. Desde esa óptica, es entonces la práctica social la que conduce hacia una representación social, y solo la presencia de una fuente de poder más compleja y elaborada que la del propio concejo generará un desequilibrio que obligará a reajustar los términos de uso. En este caso, percibidos y representados en términos de usurpación, enajenación o intromisión frente a la memoria social preservada y transmitida dentro de las comunidades. Hay una pulsión que tiene como objeto central al monte como fuente de recursos, donde se enfrentan dos representaciones sociales diferentes sobre su uso y aprovechamiento. Por un lado, el monasterio de Ońa como entidad supralocal y, por otro, los concejos, pero cada uno de ellos de manera autónoma.

El paisaje, en su dimensión natural, y su uso aparecen en primera instancia representados como un bien, dotados de un valor de producción imprescindible para cada uno de los intervinientes; es evidente que el capital natural de lo que se representa

79 Rojo Díez, Eduardo. «La fundación del monasterio de Ońa y los castillos de su entorno: los casos de Cuevarana y Petralata». En Sánchez-Domingo, Oña. Un milenio, pp. 676-690.

80 TÉvar SAnz, Gonzalo. «La cuenca visual en el análisis del paisaje». Serie Geográfica, 1996, vol. 6, pp. 99-100.

81 Serrano Giné, David. «Consideraciones en torno al concepto de unidad de paisaje y sistematización de propuestas». Estudios Geográficos, 2012, vol. LXXIII, n. ${ }^{\circ} 272$, pp. 217-218. 
es elevado para todos los agentes. Especialmente la madera, para leña o para construir ${ }^{82}$. Hay que tener en cuenta que las condiciones medioambientales del entorno de la villa de Oña, donde según hemos visto se concentran los procesos por el uso de los montes, penalizan directamente sobre los propios recursos, ya que el terreno es abrupto y escarpado, con vías de comunicación que ofrecen escasas alternativas. Como hemos anticipado, el primer código simbólico es el de visualizar e interpretar ese paisaje como utilizable, como proveedor de materia o riqueza, bien como madera, leña, caza, carbón, pasto, etc., y/o en su defecto, como fuente de bienes materiales, rentas o tributos. Desde la lógica conceptual de los intervinientes, todos admiten y aceptan su posibilidad de disfrutar y de beneficiarse de la naturaleza, de los bosques que tienen sentido como recurso porque pueden ser utilizados ${ }^{83}$. En esa misma instancia, respondería también a una representación tangible del poder, de la autoridad, pues se discute acerca de la propiedad, del control, de la pertenencia de esos espacios.

Arroyuelo y Villapanillo son dos localidades ubicadas en la Merindad de Cuesta Urría, próximas a Trespaderne, al norte de Oña. La documentación judicial sobre uso y aprovechamiento de montes y bosques relacionada con estos concejos presenta un notable interés, y un espectro cronológico muy amplio (siglos XIV-XVII). La cuestión principal que se debate se centra en la posibilidad de cortar madera en los montes de La Horadada. Ya a fecha de 6 de abril de 1320 el abad de Oña, don García, otorgaba licencia a los concejos de Arroyuelo y Villapanillo para que pudieran seguir cortando madera en los montes situados sobre la hospedería, próximos al desfiladero de La Horadada confirmando la costumbre ya autorizada por abades anteriores ${ }^{84}$. No obstante, no hemos vuelto a encontrar documentación aludiendo a los citados montes hasta 1486. En 11 de julio el monasterio de Oña está concediendo licencia a estos concejos para que puedan cortar leña en dichos términos, circunstancia que se repite en junio de 1496, cuando el abad fray Andrés de Cerezo se la vuelve a conceder. Esta situación sufre una cierta alteración a final del siglo, pues en la Chancillería de Valladolid se va a litigar por conseguir la licencia de poder cortar leña tanto en La Horadada (y esta se les concede tanto en 1499 como en 1500) como en Cuesta Solana, donde, sin embargo, se les veta la posibilidad de obtener madera. Además, contamos con que se ha conservado un pliego que recoge las diversas peticiones que, desde 1499 y durante los años 1500, 1501, 1514, $1515,1518,1520,1522,1523,1524,1526,1528,1529,1555,1559$ y 1563 , elevaron los concejos a través de sus procuradores al abad de Oña para que les permitiese cortar

82 «Después desto pagué a treinta e siete carpenteros que andovieron en faser la estacada de la puente de Tamayo a real cada uno sin los carpinteros nuestros del monasterio que andovieron con ellos de los quales non cuento cosa alguna nin tampoco cuento por agora los carros nuestros que andovieron a traer todas las estacas e maderas que fueron menester en que entraron treynta e çinco carros e tres carpenteros nuestros tres semanas e tres días de lo qual como dixe non cuento cosa alguna por agora. Así montó en los dichos XXXVII carpenteros suso dichos, IUCL mrs.». Año 1483. Cuentas del monasterio de San Salvador de Ońa. AHN. Clero. Legajo 1483.

83 Raposo Quintana, Gabriela. «El paisaje como imagen: de la construcción social al objeto de consumo». DU\&'P. Revista de Diseño Urbano y Paisaje, 2006, vol. III, n. ${ }^{\circ}$ 9, p. 11.

84 Es interesante tener presente la preocupación del monasterio en mantener accesible el desfiladero. El monasterio de San Salvador de Ońa se gastó 5.435 mrs. en 1483 en «reparar e endereçar los pasos de la Foradada», y otros 2.630 mrs. en 1484 para «reparar los pasos malos de la Horada». AHN. Clero. Legajo. 1297. 
FRANCISCO REYES TÉLLEZ Y GONZALO VIÑUALES FERREIRO PAISAJE FORESTAL Y REPRESENTACIÓN SOCIAL EN CASTILLA (SIGLOS XIV-XVI). LOS MONTES DE SAN SALVADOR DE OÑA (BURGOS)

horcas y horquillas, recoger leña, e incluso carbonear, y las respectivas licencias otorgadas por el abad. La petición de merced sigue un modelo diplomático y textual casi idéntico, y refleja un marcado automatismo en la relación con el medio. Es claramente una petición estereotipada y reiterativa, que nos conduce a pensar en un posible juego de alianzas o intereses conjuntos ${ }^{85}$. Recordemos que Arroyuelo, de acuerdo a los datos consignados en los Libros de Cuentas conservados para el siglos Xv, es la población que contribuye con más fanegas de cereal de todas en el señorío de Oña, y con una marcada ventaja respecto al resto ${ }^{86}$. Igualmente resulta curioso que en las numerosas peticiones de merced para cortar leńa que redactan los concejos de Arroyuelo y Villapanillo se haga normalmente una mención genérica a los denominados «montes de la Horadada», y solamente en un caso se especifique «en los nuestros montes de La Horadada y en la Quemada que está allende el río de Ebro que es propria deste nuestro monasterio» ${ }^{87}$.

Existe asimismo una representación social que aísla porciones culturales de ese paisaje de acuerdo a fenómenos comprensibles de división del terrazgo, límites, amojonamientos, etc. aprehendidos y aceptados por los grupos sociales. Se discute por dónde pasan o han pasado los linderos, pero todos están de acuerdo en que son necesarios y marcan o determinan una separación física. En 9 de septiembre de 1467 se dictaba una sentencia arbitraria entre el monasterio de Ońa y la villa de Tamayo, en razón de rozar y cortar en cierta parte de la sierra que llaman de Tamayo ${ }^{88}$. Situada en la vertiente del río Oca, la villa de Tamayo, hoy despoblada, es la población más próxima al monasterio de Oña ${ }^{89}$. Un procedimiento que se había iniciado en 7 de mayo de 1466, cuando se acordó la carta de compromiso por la que se nombraban los jueces árbitros, pero que estaba abierto, por lo menos desde 1414 , fecha en la que ya se dictó sentencia a favor del monasterio de Oña. Al fijarnos en algunos de los términos de dicha sentencia, observamos que de las cinco medidas del fallo solamente una implica realizar un nuevo proceso de amojonamiento («que se ponga un moxón»). Este afectaría a los montes propios del señor de las torres de Tamayo, Gonzalo García de Salazar, y del concejo y hombres buenos de Tamayo, mientras que en las cuatro descripciones restantes los límites están netamente definidos con anterioridad y parece que son aceptados sin problemas por todos los actores del contencioso («en quanto toca a los otros montes e dehesa vieja, de suso limitados y mojonados»).

Puede dar la impresión de que el paisaje es una abstracción geográfica que el abad utiliza a su antojo como señor (propiedad y control) frente a la idea comunal de uso para el concejo o los concejos. Puede ser esta circunstancia el motivo de que el monasterio

85 Escalona Monge, Julio. «Misericordia regia, es decir, negociemos. Alfonso VII y los Lara en la Cronica Adefonsi Imperatoris». En Alfonso, Isabel; Escalona, Julio y Martin, Georges (eds.). Lucha politica: condena y legitimación en la España medieval. Lyon, 2004, pp. 101-152.

86 Libro de cuentas de 1458: «En Arroyuelo ay de renta quinientos almudes de pan. D almudes». Libro de cuentas de 1494: «La prestamería de Arroyuelo quenientos e quarenta almudes de pan que son sieteçientos e veynte fanegas de la medida mayor. DCCXX fanegas». AHN. Clero. Libro 1260.

87 AHN. Clero. Legajo 1295.

88 Ruiz Gómez, Las formas del poblamiento rural, p. 1613, doc. 236.

89 Rojo Díez, Eduardo. Oña y su monasterio en el pasado de Castilla. Historia, cultura y toponimia. Contribución al milenario de su abadía benedictina (1011-2011). Oña, 2009. pp. 179-238. 
defienda con más crudeza los bosques y montes más cercanos a su coto. $\mathrm{O}$ también que el monasterio controló o supervisó la gestión de los bosques para evitar un uso indiscriminado de los recursos para fraguas, etc. Podría asimismo explicar el por qué hay una abierta consonancia entre la permisividad de uso de los bosques por parte de aquellos lugares que más contribuyen con el monasterio según los datos consignados en los registros de los Libros de Cuentas. En esa aceptación de los límites de propiedades, concejos, etc., se detallan prácticas no esperables en la percepción y representación del paisaje -la ruptura de empalizadas y el movimiento de los mojones- fundamentadas en gran medida en la concepción de que hay prácticas que eran anteriores, tradicionales, antiguas, grabadas en la memoria colectiva, que confieren identidad a los intervinientes y que les justifican. En el ámbito de la vinculación entre la representación que una comunidad local tiene de su espacio, de su paisaje, y las marcas que este deja en su identidad se percibe una cierta coherencia a través del ejercicio de la violencia contra los usurpadores $^{90}$, como se redacta en la sentencia de 7 de agosto de 1422 por el pleito entre los vecinos de Cuesta Urría y Mijangos por «la dehesa que llaman el ensynal de Urría» .

A través del análisis de la documentación parece constatarse un incremento de la presión por los bosques y montes de Ońa entre los años 1450 y 1470, periodo que coincide con el proceso de reformación del monasterio de San Salvador y su incorporación a la Congregación de San Benito de Valladolid. Atendiendo al desconcierto y desgobierno de la abadía de Ońa, que se mueve en un contexto de crisis y transformación, los concejos aprovechan para fortalecer su posición y ganar prerrogativas frente al monasterio. Se observa que en la gran mayoría de los procesos judiciales que hemos localizado se litiga contra localidades que están muy próximas en el terreno a la villa de Oña. Así es el caso de las poblaciones de Tamayo, Bentretea, Terminón, Cantabrana, Penches, Barcina de los Montes y Soto de Bureba, que se localizan dentro de un radio de acción muy cercano al monasterio de San Salvador. Solamente Arroyuelo y Villapanillo se ubican algo más distantes y alejadas de la cuenca del río Oca.

En su momento Ruiz Gómez ya planteó que la presión sobre los montes desde mediados del siglo XIV estribaba en una tendencia expansiva de ciertos concejos cercanos al propio monasterio, lo que le obligó a precisar con mayor lujo de detalles mojones, términos, etc. para evitar usurpaciones. Esta argumentación se basaba en la existencia de un documento, una carta, en la que el Adelantado Mayor del Rey, Ferrán Pérez de Portocarrero, ordenaba a los merinos que respetaran el coto y los ríos pertenecientes a Oña, y les otorgaba facultad para guardar esos montes y prender y multar a aquellos que no cumpliesen el mandato. Pocos días más tarde, se precisaban esos límites mediante una carta. Incremento de la presión que se vería justificado por un alejamiento de Ońa y de los concejos de su entorno de las principales rutas de intercambios vigentes y en alza durante el siglo XV.

90 Monsalvo Antón, José María. «Usurpación de comunales: conflicto social y disputa legal en Ávila y su tierra en la Baja Edad Media». Historia Agraria, 2011, vol. 24, pp. 89-122.

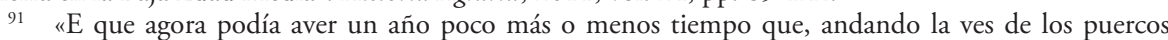
del dicho lugar de Mixangos a comer la grana e paçer las yervas según lo tenían de costumbre en la dicha dehesa, que los vecinos y moradores en el dicho lugar de Urría conçejalmente que fueran a la dicha dehesa armados de lanças, dardos e vallestas, y les tomaran y llevaran por fuerça e syn razón e syn derecho e contra sus voluntades toda la dicha ves de los puercos del dicho lugar de Mixangos». AHN. Clero. Legajo. 1214. 
FRANCISCO REYES TÉLLEZ Y GONZALO VIÑUALES FERREIRO PAISAJE FORESTAL Y REPRESENTACIÓN SOCIAL EN CASTILLA (SIGLOS XIV-XVI). LOS MONTES DE SAN SALVADOR DE OÑA (BURGOS)

Anexo 1.- Documentación sobre los montes de San Salvador de Oña

\begin{tabular}{|c|c|c|c|}
\hline Fecha & Regesto & Signatura & Referencia \\
\hline $1320 / 04 / 06$ & $\begin{array}{l}\text { El monasterio de San Salvador de Ońa, a la vista de la } \\
\text { pesquisa efectuada, concede autorización a los concejos } \\
\text { de Arroyuelo y Villapanillo para continuar utilizando los } \\
\text { montes situados sobre la hospedería. }\end{array}$ & $\begin{array}{l}\text { AHN. Clero. } \\
\text { Legajo } 1213\end{array}$ & $\begin{array}{l}\text { Oceja, } \\
(1319-1350) \\
\text { p. } 16 .\end{array}$ \\
\hline $1338 / 09 / 07$ & $\begin{array}{l}\text { Carta del adelantado mayor de Castilla, Ferrand Pérez de } \\
\text { Portocarrero, sobre los cotos de los montes y los ríos de } \\
\text { Ońa. }\end{array}$ & $\begin{array}{l}\text { AHN. Clero. } \\
\text { Carp. } 311 / 11 \\
\text { Legajo } 1282\end{array}$ & $\begin{array}{l}\text { Ruiz Gómez, p. } \\
\text { 1352, doc. } 69 .\end{array}$ \\
\hline $1338 / 09 / 07$ & $\begin{array}{l}\text { Traslado del adelantado del rey, por el que manda a todos } \\
\text { los alcaldes y justicias que no consientan cortar leña ni } \\
\text { madera en los montes pertenecientes al monasterio de } \\
\text { Ońa, ni en sus dehesas, y que nadie pesque en sus ríos ni } \\
\text { piélagos, y que nadie cace en los términos de sus lugares } \\
\text { perdices ni ninguna otra cosa, y si alguno lo hiciere, } \\
\text { que sea castigado según las penas determinadas en sus } \\
\text { privilegios. }\end{array}$ & $\begin{array}{l}\text { AHN. Clero. } \\
\text { Legajo } 1282\end{array}$ & $\begin{array}{l}\text { Ruiz Gómez, p. } \\
1354 \text {, doc. } 70 .\end{array}$ \\
\hline $1339 / 02 / 17$ & $\begin{array}{l}\text { Juan Pérez de Valluercanes, merino de las merindades de } \\
\text { Bureba y Valluercanes, ante el abad del monasterio de Oña, } \\
\text { don Alfonso, en el lugar de Bentretea, lee el diploma de } \\
\text { Ferrand Pérez de Portocarrero de fecha 1338, septiembre, } \\
\text { 7, sobre el coto de los montes y ríos del monasterio de Oña } \\
\text { que inserta. }\end{array}$ & $\begin{array}{l}\text { AHN. Clero. } \\
\text { Carp. 311/16 }\end{array}$ & $\begin{array}{l}\text { Ruiz Gómez, p. } \\
\text { 1357, doc. } 72 \text {. }\end{array}$ \\
\hline $1340 / 05 / 24$ & $\begin{array}{l}\text { D. a Teresa, viuda de Ruy Pérez de Soto, declara que los } \\
\text { montes de Domingo Sancho y de Piedra Lada pertenecen } \\
\text { al monasterio de Ońa. Ella los tuvo hasta ahora en guarda, } \\
\text { por su mandado, estando prohibido que otros entrasen a } \\
\text { cortar leńa allí. Ahora los devuelve y pide que, en adelante, } \\
\text { el monasterio ponga guardas para protegerlos. }\end{array}$ & $\begin{array}{l}\text { AHN.Clero. } \\
\text { Carp. 312/12 }\end{array}$ & $\begin{array}{l}\text { Ruiz Gómez, p. } \\
\text { 1359, doc. } 76 .\end{array}$ \\
\hline $1351 / 06$ & $\begin{array}{l}\text { Cuadernillo de privilegios de Pedro I, en papel, que fue } \\
\text { presentado en Burgos, conteniendo el traslado de las } \\
\text { siguientes disposiciones: «que no corten leńa ni pesquen } \\
\text { en ríos» (era 1389-1351-, junio, 6, Burgos). }\end{array}$ & $\begin{array}{l}\text { AHN. Clero. } \\
\text { Carp. 313/8 }\end{array}$ & $\begin{array}{l}\text { Ruiz Gómez, p. } \\
\text { 1360, doc. } 80 \text {. }\end{array}$ \\
\hline $1394 / 03 / 28$ & $\begin{array}{l}\text { Sentencia por el abad de San Fagún contra el concejo } \\
\text { de Soto, sobre los montes de Piedra Lada y Domingo } \\
\text { Sancho. En presencia del escribano Alfonso Fernández de } \\
\text { la iglesia de San Fagún, el abad de San Fagún como juez } \\
\text { confinado dado para entender en el pleito habido entre el } \\
\text { monasterio de Oña y el concejo de Soto. Comparece Pero } \\
\text { de Castroverde, vecino de Sahagún, como procurador del } \\
\text { monasterio y Johán López, hijo de Martín Ruyz, vecino } \\
\text { de Soto, en nombre del concejo, clérigos, escuderos y } \\
\text { labradores de Soto. Ambos solicitan que el abad dicte } \\
\text { sentencia sobre los montes de Domingo Soto y de Piedra } \\
\text { Lada, cercanos a Ońa que se deslindan así. }\end{array}$ & $\begin{array}{l}\text { AHN. Clero. } \\
\text { Carp. 318/6 }\end{array}$ & $\begin{array}{l}\text { Ruiz Gómez, p. } \\
\text { 1480, doc. } 153 .\end{array}$ \\
\hline
\end{tabular}


FRANCISCO REYES TÉLLEZ Y GONZALO VIÑUALES FERREIRO

PAISAJE FORESTAL Y REPRESENTACIÓN SOCIAL EN CASTILLA (SIGLOS XIV-XVI).

LOS MONTES DE SAN SALVADOR DE OÑA (BURGOS)

\begin{tabular}{|c|c|c|c|}
\hline Fecha & Regesto & Signatura & Referencia \\
\hline $1414 / 06 / 23$ & $\begin{array}{l}\text { Sentencia sobre pastos y majadas en la dehesa de Tamayo, } \\
\text { dada a favor del monasterio de San Salvador y en contra del } \\
\text { concejo de dicho lugar. }\end{array}$ & $\begin{array}{l}\text { AHN. Clero. } \\
\text { Carp. 323/7 }\end{array}$ & $\begin{array}{l}\text { Ruiz Gómez, p. } \\
\text { 1514, doc. } 181 \text {. }\end{array}$ \\
\hline $1417 / 08 / 12$ & $\begin{array}{l}\text { Sentencia dada en el pleito entre los concejos de Cornudilla } \\
\text { y Pino en razón de los términos y pastos. }\end{array}$ & $\begin{array}{l}\text { AHN. Clero. } \\
\text { Carp. 322/2 }\end{array}$ & $\begin{array}{l}\text { Ruiz Gómez, p. } \\
\text { 1515, doc. } 182 .\end{array}$ \\
\hline $1420 / 05 / 7$ & $\begin{array}{l}\text { Licencia dada por el abad del monasterio de Ońa a favor } \\
\text { del concejo de Soto para que puedan cortar leña en los } \\
\text { montes de Piedralada. }\end{array}$ & $\begin{array}{l}\text { AHN. Clero. } \\
\text { Carp. 322/11 }\end{array}$ & $\begin{array}{l}\text { Ruiz Gómez, p. } \\
1518 \text {, doc. } 184 \text {. }\end{array}$ \\
\hline $1440 / 11 / 26$ & $\begin{array}{l}\text { Sentencia entre los lugares de Cillaperlata y Valdenubla } \\
\text { sobre los pastos. }\end{array}$ & $\begin{array}{l}\text { AHN. Clero. } \\
\text { Carp. 324/3 }\end{array}$ & $\begin{array}{l}\text { Ruiz Gómez, p. } \\
\text { 1523, doc. } 192 .\end{array}$ \\
\hline $1452 / 09 / 6$ & $\begin{array}{l}\text { Pesquisa realizada entre Bentretea y Terminón y sobre pastos } \\
\text { en la dehesa de Bentretea. }\end{array}$ & $\begin{array}{l}\text { AHN. Clero. } \\
\text { Carp. 325/13 }\end{array}$ & $\begin{array}{l}\text { Ruiz Gómez, p. } \\
\text { 1528, doc. } 207 .\end{array}$ \\
\hline $1453 / 01 / 28$ & $\begin{array}{l}\text { Sentencia sobre términos y pastos entre los lugares de } \\
\text { Villanueva y Barcina. }\end{array}$ & $\begin{array}{l}\text { AHN. Clero. } \\
\text { Carp. 325/17 }\end{array}$ & $\begin{array}{l}\text { Ruiz Gómez, p. } \\
\text { 1531, doc. } 208 .\end{array}$ \\
\hline $1454 / 02 / 15$ & $\begin{array}{l}\text { Sentencia arbitraria entre Ońa y Penches sobre aprove- } \\
\text { chamiento de montes, términos y pastos. }\end{array}$ & $\begin{array}{l}\text { AHN. Clero. } \\
\text { Libro } 1217\end{array}$ & \\
\hline $1454 / 02 / 16$ & $\begin{array}{l}\text { Pleito habido entre los concejos de Ońa y Penches } \\
\text { sobre el aprovechamiento de los términos y pastos } \\
\text { colindantes. }\end{array}$ & $\begin{array}{l}\text { AHN. Clero. } \\
\text { Libro } 1217\end{array}$ & $\begin{array}{l}\text { Ruiz Gómez, p. } \\
1535 \text {, doc. } 210 .\end{array}$ \\
\hline $1454 / 09 / 24$ & $\begin{array}{l}\text { Sentencia entre Bentretea y Terminón sobre montes y } \\
\text { pastos. }\end{array}$ & $\begin{array}{l}\text { AHN. Clero. } \\
\text { Legajo } 1214\end{array}$ & \\
\hline $1454 / 12 / 4$ & $\begin{array}{l}\text { Sentencia sobre montes y términos entre los lugares de } \\
\text { Terminón y Bentretea. }\end{array}$ & $\begin{array}{l}\text { AHN. Clero. } \\
\text { Carp. 325/15 }\end{array}$ & $\begin{array}{l}\text { Ruiz Gómez, p. } \\
\text { 1552, doc. } 211 .\end{array}$ \\
\hline $1455 / 06 / 30$ & Pleito sobre los montes de Piedralada y Domingo Sancho. & $\begin{array}{l}\text { AHN. Clero. } \\
\text { Legajo } 1214\end{array}$ & \\
\hline 1458 & $\begin{array}{l}\text { Traslado de una sentencia dada en el pleito habido entre } \\
\text { el lugar de Altable y la villa de Pancorbo sobre el aprove- } \\
\text { chamiento de los términos y pastos entre ambos concejos. }\end{array}$ & $\begin{array}{l}\text { AHN. Clero. } \\
\text { Libro } 1312\end{array}$ & $\begin{array}{l}\text { Ruiz Gómez, p. } \\
\text { 1580, doc. } 231 .\end{array}$ \\
\hline 1464 & $\begin{array}{l}\text { Probanza de cómo los montes de Piedralada son del mo- } \\
\text { nasterio de Ońa contra los concejos de Soto, Quintanilla } \\
\text { y Quintana Vélez. }\end{array}$ & $\begin{array}{l}\text { AHN. Clero. } \\
\text { Legajo } 1295\end{array}$ & \\
\hline $1467 / 05 / 9$ & $\begin{array}{l}\text { Sentencia arbitraria dictada entre el monasterio de Ońa y } \\
\text { la villa de Tamayo, en razón de rozar y cortar en cierta parte } \\
\text { de la sierra que llaman de Tamayo. }\end{array}$ & $\begin{array}{l}\text { AHN. Clero. } \\
\text { Libro } 1286\end{array}$ & $\begin{array}{l}\text { Ruiz Gómez, p. } \\
\text { 1613, doc. } 236 .\end{array}$ \\
\hline $\begin{array}{l}1472-1476 \\
(1582)\end{array}$ & $\begin{array}{l}\text { Sentencia ejecutoria pronunciada en el pleito habido sobre } \\
\text { el seńorío del monasterio de Oña en el lugar de Barcina de } \\
\text { los Montes. Dada en } 1582 .\end{array}$ & $\begin{array}{l}\text { AHN. Clero. } \\
\text { Libro 1277, fols. } \\
59-73 \\
\end{array}$ & $\begin{array}{l}\text { Ruiz Gómez, p. } \\
1625 \text {, doc. } 237 .\end{array}$ \\
\hline $1474 / 08 / 13$ & $\begin{array}{l}\text { Sentencia entre Mijangos y Urría sobre el uso y aprovecha- } \\
\text { miento de la dehesa de Urría. }\end{array}$ & $\begin{array}{l}\text { AHN. Clero. } \\
\text { Legajo } 1214\end{array}$ & \\
\hline $1486 / 07 / 11$ & $\begin{array}{l}\text { Conocimiento de los vecinos de Arroyuelo cómo no } \\
\text { pueden cortar leña en los montes de la Horadada sin } \\
\text { licencia. }\end{array}$ & $\begin{array}{l}\text { AHN. Clero. } \\
\text { Legajo } 1295\end{array}$ & \\
\hline
\end{tabular}


FRANCISCO REYES TÉLLEZ Y GONZALO VIÑUALES FERREIRO PAISAJE FORESTAL Y REPRESENTACIÓN SOCIAL EN CASTILLA (SIGLOS XIV-XVI). LOS MONTES DE SAN SALVADOR DE OÑA (BURGOS)

\begin{tabular}{|c|c|c|c|}
\hline Fecha & Regesto & Signatura & Referencia \\
\hline $1487 / 05 / 13$ & $\begin{array}{l}\text { Pleito habido entre los lugares de Ońa y Tamayo, en ra- } \\
\text { zón de las agresiones sufridas por el montanero de Oña, } \\
\text { al tomar en prenda dos bueyes que habían hecho daño en } \\
\text { los cultivos. }\end{array}$ & $\begin{array}{l}\text { AHN. Clero. } \\
\text { Legajo } 1282 \\
\text { Libro } 1214 \text {, fols. } \\
261-267\end{array}$ & $\begin{array}{l}\text { Ruiz Gómez, p. } \\
\text { 1634, doc. } 243 .\end{array}$ \\
\hline $1489 / 11 / 16$ & Sobre las heredades de Castellanos. & $\begin{array}{l}\text { AHN. Clero. } \\
\text { Libro 1214, fols. } \\
245-250\end{array}$ & $\begin{array}{l}\text { Ruiz Gómez, p. } \\
\text { 1643, doc. } 246 .\end{array}$ \\
\hline $1491 / 01$ & $\begin{array}{l}\text { Que la villa de Veo devuelva un monte al monasterio de } \\
\text { San Salvador de Oña. }\end{array}$ & $\begin{array}{l}\text { AGS. RGS. } \\
\text { 1492/01, fol. } 48\end{array}$ & \\
\hline $1492 / 12 / 30$ & $\begin{array}{l}\text { Conocimiento de Fernando de Bárcena que no pudo } \\
\text { prendar en el monte de Valdeperros por ser de Oña. }\end{array}$ & $\begin{array}{l}\text { AHN. Clero. } \\
\text { Legajo } 1214\end{array}$ & \\
\hline 1496 & $\begin{array}{l}\text { Licencia que dio el abad fray Andrés de Cerezo a los lugares } \\
\text { de Arroyuelo y Villapanillo para cortar los montes de Ońa. }\end{array}$ & $\begin{array}{l}\text { AHN. Clero. } \\
\text { Legajo } 1295\end{array}$ & \\
\hline $1499 / 06 / 28$ & $\begin{array}{l}\text { Apelación de los vecinos de Arroyuelo, ante la Chancillería } \\
\text { Real, en reclamación del derecho de cortar leña en el } \\
\text { monte de Cuesta Solana y en contra del monasterio de } \\
\text { Ońa, al que emplazan por tal motivo. }\end{array}$ & $\begin{array}{l}\text { AHN. Clero. } \\
\text { Legajo } 1282\end{array}$ & $\begin{array}{l}\text { Ruiz Gómez, p. } \\
\text { 1752, doc. } 260 .\end{array}$ \\
\hline $1499 / 06 / 28$ & $\begin{array}{l}\text { Ejecutoria de pleito litigado por el concejo, justicia, y } \\
\text { regimiento de Arroyuelo (Burgos) con el monasterio de } \\
\text { San Salvador de Ońa, orden de San Benito, situado en Ońa } \\
\text { (Burgos), sobre aprovechamiento de leña y tala de montes. }\end{array}$ & $\begin{array}{l}\text { ACHVALL. } \\
\text { Ejecutorias. Caja } \\
134.41-2\end{array}$ & \\
\hline $1499 / 07 / 17$ & $\begin{array}{l}\text { Compromiso que hicieron los de Arroyuelo sobre los } \\
\text { montes en manos del señor abad de Ońa hasta el día de } \\
\text { Navidad. }\end{array}$ & $\begin{array}{l}\text { AHN. Clero. } \\
\text { Legajo } 1295\end{array}$ & \\
\hline $1499 / 12 / 20$ & $\begin{array}{l}\text { Cédula real de los RRCC para que los vecinos de Arroyuelo } \\
\text { y Villa Panillo, lugares situados en la merindad de Cuesta } \\
\text { Urría, no puedan cortar leña en el monte de Cuesta Solana. }\end{array}$ & $\begin{array}{l}\text { AHN. Clero. } \\
\text { Legajo } 1282\end{array}$ & $\begin{array}{l}\text { Ruiz Gómez, p. } \\
1753 \text {, doc. } 261 .\end{array}$ \\
\hline $1500 / 03 / 02$ & $\begin{array}{l}\text { Sentencia por la muerte de un carnero y dos ovejas del } \\
\text { monasterio en Renera y Villamayor de los Montes, gracias } \\
\text { a la intervención del Condestable de Castilla. }\end{array}$ & $\begin{array}{l}\text { AHN. Clero. } \\
\text { Legajo } 1220\end{array}$ & \\
\hline $1500 / 07 / 28$ & $\begin{array}{l}\text { Ejecutoria del pleito litigado por el concejo, justicia y } \\
\text { regimiento de Arroyuelo (Burgos), con el monasterio de } \\
\text { San Salvador de Ońa, orden de San Benito, situado en Oña } \\
\text { (Burgos), sobre el aprovechamiento de un monte. }\end{array}$ & $\begin{array}{l}\text { ACHVALL, } \\
\text { Ejecutorias Caja } \\
149-1\end{array}$ & \\
\hline $1507 / 12 / 22$ & $\begin{array}{l}\text { Mandamiento dado por el alcalde mayor de Ońa, a petición } \\
\text { del concejo y vecinos del lugar de Pino, para que cuatro } \\
\text { vecinos de este viesen los ejidos que estuviesen ocupados } \\
\text { y, bajo juramento, los declarasen, pusiesen mojones y los } \\
\text { hiciesen desocupar. }\end{array}$ & $\begin{array}{l}\text { AHN. Clero. } \\
\text { Libro } 1314\end{array}$ & $\begin{array}{l}\text { Ruiz Gómez, p. } \\
\text { 1774, doc. } 273 .\end{array}$ \\
\hline $1509 / 10 / 13$ & $\begin{array}{l}\text { Cédula real de la reina dońa Juana contra el concejo de } \\
\text { Tamayo para que sus vecinos respeten los ejidos y demás } \\
\text { bienes, posiblemente pertenecientes al monasterio de Oña. } \\
\text { Sobre lo cual está pendiente una apelación hecha ante } \\
\text { Chancillería. }\end{array}$ & $\begin{array}{l}\text { AHN. Clero. } \\
\text { Legajo } 1282\end{array}$ & $\begin{array}{l}\text { Ruiz Gómez, p. } \\
1775 \text {, doc. } 275 .\end{array}$ \\
\hline
\end{tabular}


FRANCISCO REYES TÉLLEZ Y GONZALO VIÑUALES FERREIRO

PAISAJE FORESTAL Y REPRESENTACIÓN SOCIAL EN CASTILLA (SIGLOS XIV-XVI).

LOS MONTES DE SAN SALVADOR DE OÑA (BURGOS)

\begin{tabular}{|c|c|c|c|}
\hline Fecha & Regesto & Signatura & Referencia \\
\hline $1509 / 10 / 22$ & $\begin{array}{l}\text { Notificación notarial hecha a los vecinos de Tamayo, para } \\
\text { que no talen ni destruyan los montes del dicho lugar, ni } \\
\text { vendan los ejidos, en tanto se resuelve el pleito que tienen } \\
\text { contra el monasterio de Ońa, en razón de la reclamación } \\
\text { de su seńorío ante la Chancillería Real. Si bien mientras } \\
\text { tanto, puedan aprovecharlos. }\end{array}$ & $\begin{array}{l}\text { AHN. Clero. } \\
\text { Legajo } 1282\end{array}$ & $\begin{array}{l}\text { Ruiz Gómez, p. } \\
1778 \text {, doc. } 276 .\end{array}$ \\
\hline $1512 / 03 / 03$ & $\begin{array}{l}\text { Mandamiento del alcalde mayor de Ońa para que cuatro } \\
\text { vecinos de Pino viesen el coto que se había de echar en los } \\
\text { árboles que estaban en lo concejil. }\end{array}$ & $\begin{array}{l}\text { AHN. Clero. } \\
\text { Libro } 1314\end{array}$ & $\begin{array}{l}\text { Ruiz Gómez, p. } \\
\text { 1781, doc. } 280 .\end{array}$ \\
\hline 1513 & $\begin{array}{l}\text { Mandamiento del abad de Ońa para que no se prenda } \\
\text { fuego en los montes ni ningún vecino ocupase ninguna } \\
\text { tierra en los ejidos, y para que su alcalde mayor fuese a } \\
\text { averiguar las personas que habían puesto fuego a los } \\
\text { montes y roto los ejidos. }\end{array}$ & $\begin{array}{l}\text { AHN: Clero. } \\
\text { Libro } 1314\end{array}$ & $\begin{array}{l}\text { Ruiz Gómez, p. } \\
\text { 1792, doc. } 287 .\end{array}$ \\
\hline $1529 / 01 / 03$ & $\begin{array}{l}\text { Licencia que se dio a los vasallos del lugar de Arroyuelo } \\
\text { para los montes de la Horadada. }\end{array}$ & $\begin{array}{l}\text { AHN. Clero. } \\
\text { Legajo } 1295\end{array}$ & \\
\hline $1530 / 05 / 27$ & $\begin{array}{l}\text { Licencia a los vecinos de Cornudilla para hacer un corral } \\
\text { en la sierra para defender el ganado de los lobos en los } \\
\text { montes de la sierra. }\end{array}$ & $\begin{array}{l}\text { AHN. Clero. } \\
\text { Legajo } 1295\end{array}$ & \\
\hline
\end{tabular}

